\title{
Biochemical and Structural Insights into Enzymatic Depolymerization of Polylactic Acid and Other Polyesters by Microbial Carboxylesterases
}

\author{
Mahbod Hajighasemi ${ }^{\dagger}$, Boguslaw P. Nocek ${ }^{\ddagger}$, Anatoli Tchigvintsev ${ }^{\dagger}$, Greg Brown ${ }^{\dagger}$, Robert \\ Flick $^{\dagger}$, Xiaohui Xu' ${ }^{\dagger}$, Hong Cui ${ }^{\dagger}$, Tran Hai $\$$, Andrzej Joachimiak ${ }^{\ddagger}$, Peter N. Golyshin $\S$, Alexei \\ Savchenko ${ }^{\dagger}$, Elizabeth A. Edwards ${ }^{*}, \dagger$, Alexander F. Yakunin ${ }^{*}, \dagger$ \\ tDepartment of Chemical Engineering and Applied Chemistry, University of Toronto, Toronto, \\ Ontario M5S 3E5, Canada \\ ¥The Bioscience Division, Argonne National Laboratory, Argonne, Illinois 60439, United States \\ §School of Biological Sciences, University of Bangor, Gwynedd LL57 2UW, U.K.
}

\begin{abstract}
Polylactic acid (PLA) is a biodegradable polyester derived from renewable resources, which is a leading candidate for the replacement of traditional petroleum-based polymers. Since the global production of PLA is quickly growing, there is an urgent need for the development of efficient recycling technologies, which will produce lactic acid instead of $\mathrm{CO}_{2}$ as the final product. After screening 90 purified microbial $a / \beta$-hydrolases, we identified hydrolytic activity against emulsified PLA in two uncharacterized proteins, ABO2449 from Alcanivorax borkumensis and RPA1511 from Rhodopseudomonas palustris. Both enzymes were also active against emulsified polycaprolactone and other polyesters as well as against soluble $a$-naphthyl and $p$-nitrophenyl monoesters. In addition, both ABO2449 and RPA1511 catalyzed complete or extensive hydrolysis of solid PLA with the production of lactic acid monomers, dimers, and larger oligomers as products. The crystal structure of RPA1511 was determined at $2.2 \AA$ resolution and revealed a classical $a / \beta$-hydrolase fold with a wide-open active site containing a molecule of polyethylene glycol bound near the catalytic triad Ser114-His270-Asp242. Site-directed mutagenesis of both proteins demonstrated that the catalytic triad residues are important for the hydrolysis of both monoester and polyester substrates. We also identified several residues in RPA1511 (Gln172, Leu212, Met215, Trp218, and Leu220) and ABO2449 (Phe38 and Leu152), which were not essential for activity against soluble monoesters but were found to be critical for the hydrolysis of
\end{abstract}

\footnotetext{
*Corresponding Authors: elizabeth.edwards@utoronto.ca. a.iakounine@utoronto.ca.

The authors declare no competing financial interest.

Supporting Information

The Supporting Information is available free of charge on the ACS Publications website at DOI: 10.1021/acs.biomac.6b00223. Turbidimetric PLA depolymerase assay, protein sequence alignment, phylogenetic analysis of esterase-type PLA depolymerases, effect of detergents, GPC analysis of solid PLA hydrolysis products, $\mathrm{pH}$ and $\mathrm{NaCl}$ on esterase activity, structural model of ABO2449 as well as tables of 86 ester substrates, molecular weight characteristics of solid PLA hydrolysis products, LC-MS analysis of oligomeric composition of different lactic acid species, kinetic parameters of ABO2449, and crystallographic data collection and model refinement statics of RPA1511 (PDF)
} 
PLA. Our results indicate that microbial carboxyl esterases can efficiently hydrolyze various polyesters making them attractive biocatalysts for plastics depolymerization and recycling.

\section{Graphical Abstract}

\section{Enzymatic PLA depolymerization}

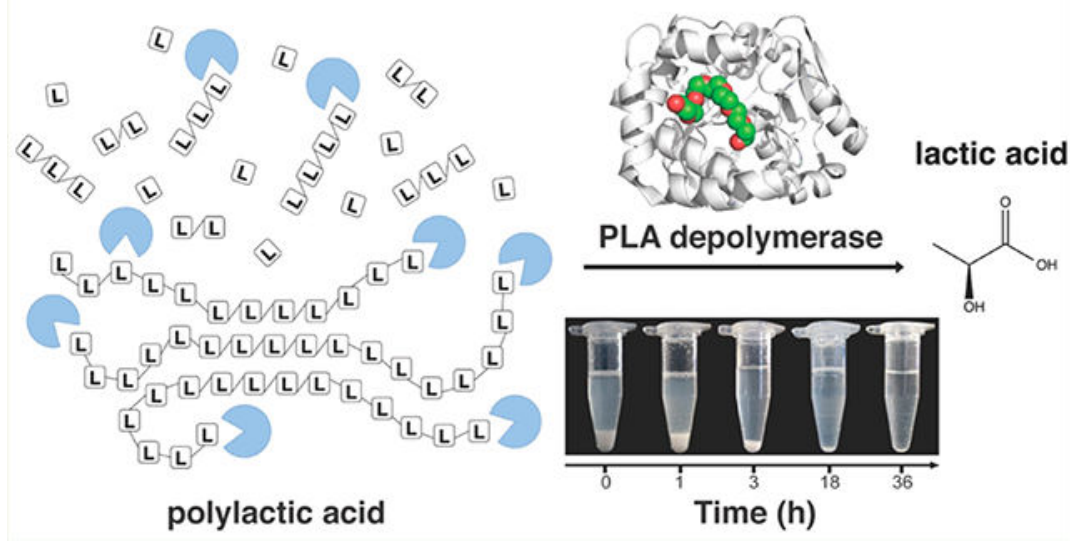

\section{INTRODUCTION}

In the second half of the 20th century, plastics became one of the most universally used and multipurpose materials. ${ }^{1}$ The annual worldwide plastics production has increased $5 \%$ during the last 20 years with almost 300 million tons of synthetic plastics produced from petroleum resources in 2014. ${ }^{2,3}$ However, global utilization of plastics in large quantities results in environmental pollution and depletion of nonrenewable natural resources. ${ }^{1,4}$ Therefore, the substitution of petroleum-based plastics with biobased and biodegradable polymers (bioplastics) is seen as an important transition because it will reduce the utilization of fossil fuels and the pressure on landfills. ${ }^{5-7}$ Polylactic acid (PLA) and polyhydroxyalkanoates (PHA) are promising bioplastics as they can be made from renewable feedstocks, they can be composted or recycled, and their production processes may be more energy efficient while preserving the stability, durability, and functionality of traditional plastics. ${ }^{8-10}$

Currently, global bioplastics production is increasing almost $40 \%$ annually with PLA and its copolymers occupying over $20 \%$ of the bioplastics market. These polymers have excellent properties including processability, transparency, biocompatibility, compostability, and low toxicity. ${ }^{11}$ PLAs are produced from renewable biomass using a combination of fermentative production of lactic acid (LA) and chemical polymerization. PLA is obtained primarily by ionic polymerization of lactide, a circular dimer of two lactic acid molecules, or directly from lactic acid by polycondensation. ${ }^{12}$ Lactic acid has two optically active (chiral) forms: L-lactic acid and D-lactic acid. Therefore, PLA can exist in different isomeric forms (LL, DD, DL) and as copolymers with other polymers. In the 1960s, PLA found its first use in the medical field as a bioabsorbable and biodegradable material. ${ }^{13}$ After 1980, growing environmental awareness, as well as rising costs and limited oil resources, brought more attention to renewable and biodegradable materials like PLA. ${ }^{9}$ There is now a rich literature 
describing the microbial degradation of PLA by fungi, actinomycetes, and bacteria (Pseudomonas, Staphylococcus, Burkholderia, Bacillus). ${ }^{9,14,15}$

Waste plastics of all kinds that have reached the end of their useful life are disposed of in either a controlled or uncontrolled way in the terrestrial or aquatic environment. ${ }^{9}$ To make most effective use of limited carbon resources, waste products must be reused or recycled. Depolymerization of PLA and other polymers and reutilization of monomers for new plastic synthesis are attractive recycling options. Physical, thermal, and chemical depolymerization have been considered and sometimes implemented by industry. ${ }^{9,16}$ Enzymatic depolymerization is a rather new recycling approach that has several advantages including low energy consumption, mild reaction conditions, and the possibility for stereospecific biopolymer degradation and enzymatic repolymerization of the resultant monomers. ${ }^{9,17,18}$

The first report on the enzymatic hydrolysis of PLA by proteases was published by Williams in $1981 .{ }^{19}$ Later, several lipases and esterases were reported to be active in PLA hydrolysis. ${ }^{20-23}$ When acid, neutral, and alkaline proteases were compared for the hydrolysis of the high molecular weight PLA, only alkaline proteases showed significant activity, whereas all commercial lipases were inactive. ${ }^{24,25}$ Subsequently, PLA degrading enzymes from different strains of Amycolatopsis were identified as proteases, the enzymes from Cryptococcus sp. strain S-2 and Aspergillus oryzae RIB40 as cutinases, whereas the Paenibacillus amylolyticus PlaA and metagenomic PlaM4 were identified as lipases, and ABO1197 and ABO1251 from Alcanivorax borkumensis as esterases. ${ }^{23,26-31}$ It has been shown that enzymatic degradation of PLA by proteinase $\mathrm{K}$ follows a surface erosion mechanism with the rate of hydrolysis proportional to the exposed surface. ${ }^{32-35}$

Most of these PLA degradation studies were performed using poly(L-lactic acid) (PLLA) as substrate, whereas only one report was published using poly(D-lactic acid) (PDLA) demonstrating that proteinase K degraded PLLA, but not PDLA. ${ }^{36}$ Recently, enzymatic degradation of PDLA was reported, and a classification of PLA depolymerases into two types, one with preference toward PLLA (type I, protease-type) and another with preference to PDLA (type II, lipase/cutinase-type), was proposed. ${ }^{13}$ This work also demonstrated that a cutinase-type enzyme from Cryptococcus sp. strain S-2 can attack amorphous regions in a PLLA/PDLA blend with a preference for PDLA. Although a significant number of PLA depolymerizing enzymes have been identified and partially characterized, the crystal structure of a PLA depolymerizing enzyme has not yet been available, and the molecular mechanisms of PLA binding and hydrolysis remain unknown.

In this study, we screened 90 purified uncharacterized microbial hydrolases and identified two PLA active esterases, ABO2449 from Alcanivorax borkumensis and RPA1511 from Rhodopseudomonas palustris. Here, we present the detailed biochemical and structural characterization of these PLA depolymerases using emulsified and solid PLA and several other polyesters as well as monoester substrates. With solid PLA as substrate, ABO2449 and RPA1511 produced a mixture of lactic acid monomers and various oligomers as hydrolysis products. The crystal structure of RPA1511 revealed an open active site with a molecule of polyethylene glycol bound near the catalytic Ser114 residue. Site-directed mutagenesis of 
both proteins identified the residues important for the hydrolysis of PLA and soluble monoester substrates.

\section{EXPERIMENTAL SECTION}

\section{Materials}

All substrates used in this project (if not stated otherwise) were of analytical grade with uncapped polymer ends, purchased from Sigma-Aldrich (St. Louis, MO, USA) including poly(D,L-lactide) PLA10 (average molecular weight $\left.M_{\mathrm{w}} 1.0-1.8 \times 10^{4}\right)$ and PLA18 $\left(M_{\mathrm{W}}\right.$ $\left.1.8-2.4 \times 10^{4}\right)$, as well as polycaprolactone PCL10 $\left(M_{\mathrm{w}} 1.0 \times 10^{4}\right)$, PCL $45\left(M_{\mathrm{W}} 4.5 \times 10^{4}\right)$, PCL70 $\left(M_{\mathrm{w}} 7.0-9.0 \times 10^{4}\right)$, poly(D,L-lactide-co-glycolide), poly(ethylene succinate), poly [(R)-3-hydroxybutyric acid], and poly(3-hydroxybutyric acid-co-3-hydroxyvaleric acid). Poly(D,L-lactide) PLA2 $\left(M_{\mathrm{w}} 0.2 \times 10^{4}\right)$ and PLA70 $\left(M_{\mathrm{w}} 7.0 \times 10^{4}\right)$, poly(L-lactide) PLLA40 $\left(M_{\mathrm{w}} 4.0 \times 10^{4}\right)$, poly(D-lactide) PDLA10 $\left(M_{\mathrm{w}} 1.0-1.5 \times 10^{4}\right)$, and the decanoyl capped poly(D,L-lactide) PLA10 substrates with the blocked alcohol or acid or both polymer ends were obtained from PolySciTech (Akina Inc., West Lafayette, IN, USA). Commercial-grade PLA polymers (IngeoTM 4032D, and IngeoTM 6400D) were products of NatureWorks LLC, NE, USA, whereas polybutylene succinate (BionolleTM 1001MD, and BionolleTM 1020MD) and polybutylene succinate-co-adipate (BionolleTM 3001MD, and BionolleTM 3020MD) were supplied by Showa Denko K.K., Japan. Plysurf A210G, the surfactant used in polymer emulsification, was purchased from Dai-ichi Kogyo Seiyaku Co. (Tokyo, Japan).

\section{Gene Cloning, Mutagenesis, and Protein Purification}

The ABO2449 and RPA1511 coding sequences (GenBank accession numbers YP_694169 and NP_946859 respectively) were PCR amplified using Al. borkumensis and $R$. palustris genomic DNA as the templates. The PCR products were cloned as described previously into a modified pET15b (Novagen) vector containing an N-terminal 6His tag. ${ }^{37}$ The plasmids were transformed into Escherichia coli BL21 (DE3) Codon-Plus strain (Stratagene) as expression host. Recombinant proteins were overexpressed and purified to homogeneity (>95\%) using metal-chelate affinity chromatography on Ni-NTA Superflow $\left(\mathrm{Ni}^{2+}\right.$ nitrilotriacetate; Qiagen) resin as well as ion exchange chromatography on a Mono Q GL 10/100 column (GE Healthcare) equilibrated with $10 \mathrm{mM}$ HEPES (pH 7.5), 0.25 M NaCl, and $1 \mathrm{mM}$ TCEP [tris(2-carboxyethyl)phosphine]. ${ }^{37}$ The amino acid residues of interest were mutated to alanine using a method based on the QuickChange site-directed mutagenesis kit (Stratagene). Wild type ABO2449 and RPA1511 gene constructs in pET15b vector were used as templates, and mutations were verified by DNA sequencing. The overexpression and purification of mutant proteins were conducted in the same manner as described for wild-type proteins. Multiple sequence alignment was conducted on the EMBLEBI server powered by Clustal Omega v1.2.1, whereas the phylogenetic analysis was performed using MEGA v6.06 and neighbor-joining method. ${ }^{38,39}$

\section{Enzymatic Assays}

To measure the carboxyl esterase activity, $p \mathrm{NP}$ ( $p$-nitrophenyl) or $a$-naphthyl esters of different fatty acids $(0.25-2.0 \mathrm{mM})$ were used as substrates in a reaction mixture containing $50 \mathrm{mM}$ HEPES-K buffer ( $\mathrm{pH} 8.0$ ) and enzyme (0.05-10.0 $\mu \mathrm{g}$ of purified protein/reaction). ${ }^{37}$ 
Enzymatic assays were conducted in triplicate at the standard temperature of $30{ }^{\circ} \mathrm{C}$ in a $96-$ well plate format with $200 \mu \mathrm{L}$ of total volume of each reaction mixture. The amount of $p$ nitrophenol or $a$-naphthol released was quantified spectrophotometrically at $410 \mathrm{~nm}(\varepsilon=$ $\left.15.0 \mathrm{mM}^{-1} \mathrm{~cm}^{-1}\right)$ and $310 \mathrm{~nm}\left(\varepsilon=3.0 \mathrm{mM}^{-1} \mathrm{~cm}^{-1}\right)$, respectively. The hydrolytic activity against a library of 86 monoester substrates (Table S1) was assayed spectrophotometrically using a pH shift-based assay as described previously. ${ }^{31}$ Briefly, the reaction mixtures (150 $\mu \mathrm{L}$ ) containing $2 \mathrm{mM} \mathrm{BES} \mathrm{buffer} \mathrm{(} \mathrm{pH} 7.2), 0.45 \mathrm{mM} p$-nitrophenol, $2 \mathrm{mM}$ different ester substrates, and $0.1-2 \mu \mathrm{g}$ of enzymes were incubated at $30^{\circ} \mathrm{C}$ for $10 \mathrm{~min}$, and the esterase activity was calculated based on the absorbance of $p$-nitrophenol at $404 \mathrm{~nm}\left(\varepsilon=17.3 \mathrm{mM}^{-1}\right.$ $\mathrm{cm}^{-1}$ ) due to the $\mathrm{pH}$ shift. To determine the $K_{\mathrm{m}}$ and $K_{\mathrm{cat}}$ values, the enzymatic assays were conducted using substrates at concentrations of $0.005-2.0 \mathrm{mM} .{ }^{37}$ Kinetic parameters were determined by curve fitting (nonlinear regression) from the Lineweaver-Burk plot using GraphPad Prism software (version 5.0 for Mac, GraphPad Software, CA, USA).

\section{Analysis of Polyester-Degrading Activity}

To determine the polyester hydrolysis activity, emulsified PLA and other aliphatic polyesters were used as substrates. The polymer emulsions were prepared as described previously ${ }^{40}$ except that $50 \mathrm{mM}$ Tris- $\mathrm{HCl}$ buffer ( $\mathrm{pH} 8.0)$ was used as the aqueous phase. The polymer emulsions were solidified with agarose $(1.5 \%, \mathrm{w} / \mathrm{v})$ to make a uniformly turbid gel in 150 $\mathrm{mm}$ cell culture dishes with $20 \mathrm{~mm}$ grids. Thirty-two wells ( $3 \mathrm{~mm}$ diameter) were punched aseptically in the agarose gel, and each well was loaded with purified proteins ( $20 \mu \mathrm{L} /$ well, $5-50 \mu \mathrm{g}$ ) to be screened for polyester-degrading activity. Sealed plates were incubated at $30{ }^{\circ} \mathrm{C}$ for 3 weeks and visually inspected on a daily basis. The formation of a translucent halo around the well was interpreted as the presence of polyester-degrading activity in the protein in the well. ${ }^{40}$ In a quantitative approach, polymer emulsions were diluted with 50 $\mathrm{mM}$ Tris- $\mathrm{HCl}$ buffer ( $\mathrm{pH}$ 8.0) to obtain a consistent turbidity with a final optical density (OD 580$) 1.0-1.2$ at $580 \mathrm{~nm}$. Enzyme assays (total volume $200 \mu \mathrm{L}$ ) were conducted by adding $50 \mu \mathrm{g}$ of purified protein to each reaction in 96 -well plates at $30{ }^{\circ} \mathrm{C}$ for $2 \mathrm{~h}$. The optical density of reaction mixtures was monitored at 5 min intervals, and the decreased turbidity was interpreted as the presence of polyester-degrading activity. ${ }^{23}$ To identify depolymerase activity toward solid PLA substrates, a certain amount of PLA powder (10-12 $\mathrm{mg}$ ) was incubated in a $1.0 \mathrm{~mL}$ reaction mixture $(0.4 \mathrm{M}$ Tris- $\mathrm{HCl}$ buffer, $\mathrm{pH} 8.0,50 \mu \mathrm{g}$ of enzyme) for $36 \mathrm{~h}$ at $35^{\circ} \mathrm{C}$ with shaking. Samples were taken at different time intervals, clarified using centrifugal filters with a poly(ether sulfone) (PES) membrane (MW cutoff 10 $\mathrm{K}$ ), and subjected to lactate measurement using a lactate dehydrogenase (LDH) assay, ${ }^{41}$ which enabled the detection of both D- and L-enantiomers of lactic acid with high sensitivity. In parallel, the $90 \mu \mathrm{L}$ flow-through aliquots were treated with $10 \mathrm{M} \mathrm{NaOH}(10 \mu \mathrm{L})$ at high temperature $\left(95^{\circ} \mathrm{C}, 5 \mathrm{~min}\right)$ before lactate measurement to convert all oligomeric lactate products to monomeric lactic acid. While L-lactic acid dehydrogenase from rabbit muscle was purchased from Sigma-Aldrich (St. Louis, MO, USA), the D-lactic acid dehydrogenase (DLDH3) from Lactobacillus jensenif ${ }^{42}$ was heterologously expressed in E. coli and purified in our lab. Both enzymes were added in excess $(500 \mu \mathrm{g} / \mathrm{mL})$ to maintain the reaction rate in the first order with lactate concentration. 


\section{LC-MS Analysis}

The analysis of the PLA depolymerization products was performed using reverse phase liquid chromatography ${ }^{43}$ coupled with mass spectrometry (LC-MS). Briefly, the aqueous phase of solid PLA10 depolymerase assays was collected, filtered by centrifugation, and directly applied to the LC-MS instrument. The platform consists of a Dionex Ultimate 3000 UHPLC system and a Q-Exactive mass spectrometer equipped with a HESI source (all from Thermo Scientific). Control of the system and data handling were performed using Thermo XCalibur 2.2 software and Chromeleon 7.2 software. Product separation by liquid chromatography was conducted on a Varian C18 column $(3.9 \mathrm{~mm} \times 150 \mathrm{~mm}, 5 \mu \mathrm{m}$ particle size) equipped with a guard column. The pump was run at a flow rate of $300 \mu \mathrm{L} / \mathrm{min}$.

Solvent A was water containing $0.05 \%$ formic acid, and solvent B was $0.05 \%$ formic acid in acetonitrile. The gradient was $0-5.7 \mathrm{~min} 2 \% \mathrm{~B}, 5.7-76.5 \mathrm{~min}$ gradient to $100 \% \mathrm{~B}, 76.5-86$ $\min 100 \% \mathrm{~B}$, followed by equilibration at $2 \% \mathrm{~B}$ for $9 \mathrm{~min}$. Autosampler temperature was maintained at $4{ }^{\circ} \mathrm{C}$, and injection volume was $10 \mu \mathrm{L}$. Data collection was done in negative ionization mode with a scan range $\mathrm{m} / z$ 80-1000, resolution 70000 at $1 \mathrm{~Hz}$, AGC target of $3 \mathrm{e} 6$, and a maximum injection time of $200 \mathrm{~ms}$.

\section{Gel Permeation Chromatography (GPC) Analysis}

After enzymatic treatment, the remaining solid PLA was collected by centrifugation, dissolved in tetrahydrofuran (THF), cleared by filtration through syringe filters (CHROMSPEC, $0.22 \mu \mathrm{m}$ ), and analyzed by GPC using a Waters 2695 GPC system equipped with an RI detector (Waters 2414) and a PDA detector (Waters 2998) as well as two tandem Styragel columns $\left(5 \mu \mathrm{m}, \mathrm{HR} 4 \mathrm{E} 7.8 \mathrm{~mm} \times 300 \mathrm{~mm}, 30^{\circ} \mathrm{C}\right)$. THF was used as the eluent at a flow rate of $1.2 \mathrm{~mL} \mathrm{~min}^{-1}$. Molecular weight of reaction products was determined using a linear calibration curve determined with narrow dispersed polystyrene standards (580$156000 \mathrm{Da})$.

\section{Protein Thermodenaturation Studies}

The thermostability of the enzymes was measured using static light scattering on a StarGazer instrument as described previously. ${ }^{44}$ The protein samples in $50 \mu \mathrm{L}$ aliquots $(0.4$ $\mathrm{mg} / \mathrm{mL}$ ) were added to each well of a clear-bottom 384-well plate (Nunc, Rochester, NY) containing buffer solutions of different $\mathrm{pH}$ values and overlaid with $50 \mu \mathrm{L}$ of degassed mineral oil. The protein aggregation was monitored with a CCD (charged-coupled device) every $30 \mathrm{~s}$ following a temperature increase from 27 to $80^{\circ} \mathrm{C}$ at a rate of $1{ }^{\circ} \mathrm{C} / \mathrm{min}$. The changes in scattered light were interpreted to different pixel intensities recorded from each well. The resulting data were integrated and plotted as a function of temperature increase and fitted to the Boltzman equation by nonlinear regression. The temperature of aggregation $\left(T_{\text {agg }}\right)$ was defined as the inflection point of resulting curves for each protein. ${ }^{44}$

\section{Crystallization and Structure Determination of RPA1511}

The sitting-drop vapor-diffusion method was used to obtain selenomethionine-substituted crystals of RPA1511 at room temperature. Crystals were grown by mixing $1 \mu \mathrm{L}$ of the protein $(10 \mathrm{mg} / \mathrm{mL})$ with $1 \mu \mathrm{L}$ of the crystallization solution containing $(0.2 \mathrm{M} \mathrm{K}$ thiocyanate, 20\% PEG 3350, 4\% Jeffmine M-600, 1/300 trypsin). Crystals were stabilized 
with crystallization buffer containing 7\% of PRG 200, 7\% sucrose, and 7\% glycerol, followed by cryoprotection in Paratone-N prior to flash freezing in liquid nitrogen. RPA1511 crystals belong to the orthorhombic space group I222, with the unit cell parameters $a=80, b$ $=87.4, c=93.7, a=\beta=\gamma=90^{\circ}$ (Table S5). Data were collected at the beamline 19-ID of the Structural Biology Center, Advanced Photon Source, Argonne National Laboratory 45 and processed using the program HKL3000. ${ }^{46}$ The structure of RPA1511 was determined by SAD phasing, density modification, and model building as implemented in the HKL3000 software package. An initial model was rebuilt manually using the program $\mathrm{COOT}^{47}$ and refined with the PHENIX ${ }^{48}$ and REFMAC $^{49}$ programs. The final model was refined to $R_{\text {work }} / R_{\text {free }}=0.181 / 0.221$, and it showed good geometry with no outliers in the Ramachandran plot. Data collection and refinement statistics are summarized in Table S5. Electrostatic calculations of RPA1511 surface potential were performed using the PDB2PQR server and APBS program and were rendered using Pymol. ${ }^{50,51}$ The atomic coordinates have been deposited in the Protein Data Bank, with accession code 4PSU.

\section{RESULTS AND DISCUSSION}

\section{Screening of Purified $a / \beta$-Hydrolases for Hydrolytic Activity against PLA}

To identify novel PLA degrading enzymes, we screened 90 purified uncharacterized hydrolases from sequenced microbial genomes using two high-throughput assays, an agarose gel-based solid phase assay, and a liquid turbidimetric assay. Both assays were performed with the poly(D,L-lactic acid) substrate PLA10 with uncapped (free) polymer ends and emulsified using Plysurf A210G as emulsification detergent. The recently identified PLA degrading enzyme PlaM4 from a metagenomic gene library ${ }^{29}$ was used as a positive control. Both screens demonstrated the presence of PLA depolymerase activity in the microbial proteins ABO2449 from Al. borkumensis and RPA1511 from R. palustris (Figure 1, Table 1, Figure S1). ABO2449 showed the highest activity in both agar-based and liquid turbidimetric assays, clearing the reaction mixture within $1 \mathrm{~h}$ of incubation at $30^{\circ} \mathrm{C}$ (Figure 1, Figure S1). PlaM4 was more active than RPA1511 in agar-based screens, but RPA1511 showed higher activity in the absence of detergents (Figure 2). Although PlaM4 was capable of producing a clear halo on agarose plates containing emulsified PLA10 within $48 \mathrm{~h}$, it catalyzed only a 58\% reduction in turbidity in a liquid turbidimetric assay with the same substrate. The solid-phase agarose clearance assay provided higher sensitivity compared to the liquid turbidimetric protocol, especially with high molecular weight PLA.

Purified ABO2449 and RPA1511 were also tested for hydrolytic activity against a range of emulsified PLA polymers and other polyesters with different molecular weights and enantiomeric compositions (Table 1). On the basis of solid-phase agarose clearance assays, both RPA1511 and ABO2449 degraded several poly(D,L-lactide) substrates with different chain lengths including PLA2, PLA10, PLA18, and PLA70. However, these enzymes and PlaM4 were inactive against the enantiopure emulsified poly(L-lactide) and solid poly(Dlactide) suggesting that they hydrolyze only PLA substrates with repetitive D,L units. This might be attributed to a higher degree of crystallinity of enantiopure polymers thereby decreasing the polymer degradation. ${ }^{52}$ However, proteinase $\mathrm{K}$ and the cutinase-like enzyme 
from Cryptococcus sp. strain S-2 hydrolyzed both amorphous and homocrystalline regions of PLLA and PDLA, respectively. ${ }^{13}$

Both RPA1511 and ABO2449 were also active against polycaprolactone (MW 10K, 45K, and 70K), poly(D,L-lactide-co-glycolide), and poly(butylene succinate-co-adipate) (PBSA; Bionolle 3001MD and Bionolle 3020MD) (Table 1). In contrast to RPA1511, ABO2449 also hydrolyzed poly(3-hydroxybutyric acid-co-3-hydroxyvaleric acid), poly(ethylene succinate), and the commercial-grade polyesters Ingeo 6400D and Ingeo 4200D (Table 1). However, both enzymes were inactive against poly[(R)-3-hydroxybutyric acid] (PHB), Bionolle poly(butylene succinate) 1001MD, and Bionolle poly(butylene succinate) 1020MD. Of the two extracellular PHB depolymerases recently purified from Pseudomonas mendocina, PHAase I showed no activity against PLA, whereas PHAase II degraded both PHB and PLA. ${ }^{53}$ The polymeric substrate profile of RPA1511 was similar to that of PlaM4, whereas $\mathrm{ABO} 2449$ showed a broader substrate range.

\section{Sequence Analysis of ABO2449 and RPA1511}

On the basis of sequence, both $\mathrm{ABO} 2449$ and RPA1511 belong to the vast $a / \beta$ hydrolasefold superfamily, which includes structurally related proteins with diverse catalytic and noncatalytic functions. ${ }^{54} \mathrm{~A}$ GenBank search revealed 38 uncharacterized proteins homologous to ABO2449 (42-90\% sequence identity), mostly from hydrocarbonoclastic (oil-degrading) bacteria including Alcanivorax spp., Amycolicicoccus subflavus, Marinobacter nanhaiticus, and Hydrocarboniphaga effusa, as well as from Rhodopseudomonas palustris and several Bradyrhizobiacea. Similarly, the list of proteins homologous to RPA1511 includes several proteins from different strains of $R$. palustris and Bradyrhizobium spp. (69-99\% sequence identity). Many of the RPA1511 homologous sequences are annotated as protoporphyrin IX magnesium chelatase accessory proteins, but the presence of this activity has not been demonstrated experimentally. ABO2449 and RPA1511 showed low sequence similarity to each other (less than 30\% sequence identity), which was limited to the catalytic triad residues and several hydrophobic residues (Figure S2).

We also analyzed the phylogenetic relatedness of ABO2449 and RPA1511 to the previously characterized PLA and PHB depolymerases including both protease- and cutinase/esterasetype enzymes as well as representative esterases and lipases from different families. ${ }^{55} \mathrm{As}$ shown in Figure S3, both ABO2449 and RPA1511 clustered with the esterases from family $\mathrm{V}$, which also include poly(3-hydroxyalkanoate) depolymerase PhaB from Pseudomonas oleovorans, whereas known esterase-type PLA depolymerases were associated with other phylogenetic groups (Figure S3). In the esterase family V, both ABO2449 and RPA1511 clustered with the poly(3-hydroxyalkanoate) depolymerase PhaB from Ps. oleovorans, ${ }^{55,56}$ but they belong to different subfamilies (Figure S3). On the other hand, most of known PLA depolymerases including metagenome-derived PlaM4, PlaM5, PlaM7, and PlaM8, as well as the PLA depolymerase PlaA from Paenibacillus amylolyticus, were associated with esterase family I, whereas the metagenomic PLA depolymerase PlaM9 belongs to esterase family VI (Figure S3). Type II polyester hydrolyzing enzymes (lipase/cutinase-type) including PLA 
depolymerases are distributed across esterase families I, V, and VI and exhibit significant phylogenetic diversity.

\section{Hydrolysis of Solid PLA by ABO2449 and RPA1511}

For applications in enzyme-based PLA recycling, it is important that PLA depolymerases hydrolyze solid PLA. It has been proposed that the binding of PLA degrading enzymes to solid PLA particles and their depolymerization are impeded by the hydrophobic nature of the PLA surface and degree of crystallinity. ${ }^{29,57}$

Therefore, we also determined PLA depolymerization activity of RPA1511 and ABO2449 against solid PLA10 powder by measuring the amount of lactic acid produced using lactate dehydrogenase as a reporter enzyme. RPA1511 released significant amounts of lactic acid (as a mixture of monomers and oligomers) from solid PLA10 and degraded almost $40 \%$ of PLA within $36 \mathrm{~h}$ of incubation (Figure 2). In the absence of detergent, ABO2449 produced little lactic acid during this incubation time, but in the presence of $0.1 \%$ Plysurf A210G it quickly degraded solid PLA10 (90\% conversion) to lactic acid (Figure 2). We suggest that this detergent facilitates binding of ABO2449 to solid PLA because the detergent showed no stimulating effect on the enzyme activity against the monoester substrate $a$-naphthyl propionate (Figure S4). In contrast, the assays with $a$-naphthyl propionate revealed significant inhibition of the three enzymes by Plysurf A210G, Triton X-100, and Tween-20 at concentrations $0.1-0.5 \%$. Compared to PlaM4, RPA1511 was more sensitive to the presence of detergents (Figure S4) explaining the lower activity of this enzyme in agar-based screens with emulsified PLA (Figure 1).

The insoluble products of solid PLA hydrolysis by ABO2449 and RPA1511 were analyzed by GPC, whereas liquid LC-MS was used for the analysis of soluble reaction products (Figure 3, Figure S5). After $2 \mathrm{~h}$ of enzyme incubation with solid PLA18, GPC analysis of the PLA particles dissolved in THF revealed the presence of one major PLA product for RPA1511 with number-average molecular weight (Mn) of $186 \mathrm{Da}$, whereas two product peaks were found for $\mathrm{ABO} 2449$ (Mn 374 and $72 \mathrm{Da}$, see Table S2). This is consistent with higher hydrolytic activity of ABO2449 compared to RPA1511.

After incubation of enzymes with solid PLA10, the soluble reaction products were separated on a C18 column and analyzed using an Orbitrap MS system. As shown in Figure 3, ABO2449 and RPA1511 produced similar sets of hydrolysis products including lactic acid monomers and oligomers with different chain lengths $(n=2-13)$. Longer PLA oligomers could not be reliably detected due to their low aqueous solubility. The observed mass-tocharge ratios of all products were in accordance with the expected theoretical values of detected molecules (Table S3).

Product analysis of solid PLA hydrolysis by ABO2449 and RPA1511 suggests that like other hydrolases active against polymeric substrates (e.g., nucleases and proteases), ABO2449 and RPA1511 can potentially exhibit both exo- and endoesterase types of cleavage. This is supported by significant activity of both enzymes against both emulsified and solid PLA10 substrates with the decanoyl-capped alcohol, or acid, or both polymer ends ( $0.3 \%$ to $32 \%$ of that with uncapped PLA). This is in accordance with previous reports on 
PHB and PLA degrading enzymes suggesting the presence of both endo- and exotype of hydrolysis. ${ }^{13,32,57,58}$ In addition, our results indicate that in carboxyl esterases, the ability to cleave insoluble substrates is not limited to lipases (family I) but can also be observed in carboxyl esterases from the family V.

\section{Hydrolytic Activity of ABO2449 and RPA1511 against Monoester Substrates}

In addition to polyester substrates, both ABO2449 and RPA1511 were also active against a range of soluble naphthyl- and nitrophenyl-esters with different acyl chain lengths (C1-C5) with the highest activity against the $\mathrm{C} 2-\mathrm{C} 4$ substrates (Figure 4).

Similar to our results with polyester substrates, ABO2449 was more active than RPA1511 (Figure 4). By using $a$-naphthyl propionate as substrate, both enzymes exhibited significant activity within a broad $\mathrm{pH}$ range ( $\mathrm{pH} 7-11$ ) with the maximal rates of hydrolysis at $\mathrm{pH} 9.5-$ 10.0 (Figure S6). This is close to the optimal $\mathrm{pH}$ for PLA depolymerization reported for the esterase PlaA from Paenibacillus amylolyticus, ${ }^{23}$ and proteases from Amycolatopsis sp. strain K104-1 ${ }^{28}$ and Am. orientalis ssp. orientalis. ${ }^{59}$ Both proteins retained significant esterase activity in the presence of up to $3 \mathrm{M} \mathrm{NaCl}$ (Figure S6). While the maximal activity of $\mathrm{ABO} 2449$ was observed in the absence of $\mathrm{NaCl}$, RPA1511 was slightly stimulated at 0.5 $\mathrm{M} \mathrm{NaCl}$, but higher $\mathrm{NaCl}$ concentrations were inhibiting. For practical applications, alkaliphilic and salt-resistant PLA depolymerases would be of particular interest since they can be used for PLA depolymerization in combination with chemical catalysts. Both enzymes hydrolyzed $a$-naphthyl propionate within a broad range of temperatures but had dissimilar temperature profiles (Figure 5).

ABO2449 showed the highest esterase activity at $30-37^{\circ} \mathrm{C}$, whereas for RPA1511 the optimal temperature was $55-60{ }^{\circ} \mathrm{C}$. At $5{ }^{\circ} \mathrm{C}$, ABO2449 retained $32 \%$ of its maximal activity (observed at $30^{\circ} \mathrm{C}$ ) suggesting that it is a cold-adapted esterase, which is consistent with the ability of Al. borkumensis to grow at $4{ }^{\circ} \mathrm{C} .{ }^{60}$ Compared to ABO2449, RPA1511 retained higher activity at $55-65{ }^{\circ} \mathrm{C}$ that is typical for mesophilic esterases (Figure 5). The temperature profiles for esterase activity of ABO2449 and RPA1511 correlated with their overall thermostability determined by measuring protein aggregation as a function of temperature. These assays revealed a significantly lower thermostability of ABO2449 ( $T_{\text {agg }}$ $\left.=32.3 \pm 0.5^{\circ} \mathrm{C}\right)$ compared to that of RPA1511 $\left(T_{\text {agg }}=70.8 \pm 0.5^{\circ} \mathrm{C}\right)$, which is in accordance with the observed psychrophilicity of the former.

To further characterize the substrate range of $\mathrm{ABO} 2449$ and RPA1511, the purified proteins were screened against a library of 86 soluble monoester substrates using a $\mathrm{pH}$ shift assay (Table S1). Both enzymes exhibited significant esterase activity toward different alkyl and aryl esters (Figure 6). RPA1511 showed the highest activity against tricaprylin (C8 acyl chains) and tricaproin (C6 acyl chains), whereas ABO2449 preferred tributyrin (C4). Both enzymes were also active against several halogenated alkyl and aryl esters (Figure 6). The enantioselectivity of the two enzymes was evaluated using eight pairs of stereoisomeric monoesters as substrates (Table S1; substrates 1-10, 44-49). Only RPA1511 showed activity against $(1 R)-(-)$-neomenthyl acetate, suggesting a preference toward $(R)$-enantiomers (Figure 6). 
ABO2449 exhibited saturation kinetics with most of the positive monoester substrates (except for $a$-naphthyl butyrate and $p$-NP-propionate) with high catalytic rates against both $a$-naphthyl and $p$-NP substrates (Table S4). This enzyme has the highest affinity (low $K_{\mathrm{m}}$ ) to vinyl laurate $\left(K_{\mathrm{m}} 0.12 \mathrm{mM}\right)$ and $a$-naphthyl acetate $\left(K_{\mathrm{m}} 0.24 \mathrm{mM}\right)$ and high catalytic efficiency $\left(k_{\mathrm{cat}} / K_{\mathrm{m}}\right)$ toward $\boldsymbol{a}$-naphthyl acetate, $\boldsymbol{a}$-naphthyl propionate, and $p$ NP-butyrate (Table S4). In contrast to ABO2449, RPA1511 showed no saturation kinetics with monoester substrates suggesting that the reaction rate might be limited by the binding of these substrates to RPA1511.

\section{Crystal Structure and Active Site of RPA1511}

Purified RPA1511 and ABO2449 were subjected to crystallization trials, and the crystal structure of RPA1511 was determined at $2.2 \AA$ resolution (Table S5) using the diffraction data collected from seleno-methionine-substituted crystals of the protein. The structure revealed a core domain with a classical $\alpha / \beta$ hydrolase fold and an all- $\alpha \mathrm{U}$-shaped lid domain (Figure 7A).

Although the analysis of the crystal contacts using the quaternary prediction server PISA suggested that RPA1511 may form dimers or tetramers in solution, the results of sizeexclusion chromatography of RPA1511 suggest that the protein exists as a mixture of monomers and trimers in solution (observed molecular mass, 43.9 and $123.5 \mathrm{kDa}$; predicted molecular mass, $34.1 \mathrm{kDa}$ ). Like in the "canonical" $a / \beta$ hydrolase fold, ${ }^{61}$ the core domain $\beta$ sheet of RPA1511 contains eight parallel $\beta$-strands, with the exception of the antiparallel $\beta 2$ (Figure 7A). The $\beta$-sheet is surrounded by four $a$-helices on one side and three $a$-helices on another side. On the top, the core domain is covered by five $a$-helices forming a lid domain. It has a U-like shape and is positioned above the catalytic Ser114 leaving the active site cavity open and accessible to solvent (Figure 7A).

A Dali search ${ }^{62}$ for structurally homologous proteins in the PDB revealed hundreds of homologous $\alpha / \beta$ hydrolases with top homologous structures including meta-cleavage product hydrolases from Sphingomonas wittichii (PDB code 4LYD, Z-score 30.5, rmsd 2.2 $\AA$ ) and Janthinobacterium sp. strain J3 (PDB code 1J1I; z-score 30.2, rmsd $2.1 \AA$ ) that catalyze $\mathrm{C}-\mathrm{C}$ bond hydrolysis as part of various aromatic degradation pathways. Other similar structures include the putative lipase Lip1 from Acinetobacter baumannii AYE (PDB code 4OPM; Z-score 29.1, rmsd 2.4 $\AA$ ) and the fluoroacetate dehalogenase RPA1163 from R. palustris (PDB code 3R41; Z-score 29.0, rmsd 2.5). However, in our experiments, the purified fluoroacetate dehalogenase RPA1163 showed no hydrolytic activity against PLA10 both in plate-based and liquid turbidimetric screens indicating that additional structural features beyond those in common must contribute to the presence of PLA depolymerization activity.

The crystal structure of RPA1511 also revealed a Ser hydrolase catalytic triad with the nucleophilic Ser114 located on the classical nucleophilic elbow that is a short loop connecting the $\beta 5$ strand and $a 4$ helix (Figure 7). The RPA1511 catalytic triad also includes His270 (3.4 ̊̊ from Ser114) and Asp242 (2.7 Å from His270) (Figure 7D). On the basis of a classical Ser hydrolase mechanism, the nucleophilic Ser114 is deprotonated by the His270Asp242 general base and attacks the carbon atom of the ester bond carbonyl group. The 
produced tetrahedral intermediate- 1 is stabilized by hydrogen bonds with the RPA1511 oxyanion hole, which on the basis of the RPA1511 structure appears to include the main chain NH groups of Ala115 and Thr48 (3.1 and $5.2 \AA$ to Ser114, respectively). As shown in Figure 7, the substrate acyl-binding pocket of RPA1511 is located to the right of the catalytic Ser114 and includes several hydrophobic residues (Ile245, Val249). The larger alcoholbinding pocket is positioned to the left of Ser114 and contains both hydrophobic and polar residues (e.g., Thr48, His113, Phe169, Tyr198, Val202, Leu212). Since crystallization trials with purified ABO2449 were unsuccessful, a homology model of this enzyme was generated using the protein structure prediction server Phyre $2,{ }^{63}$ which suggested that its catalytic triad includes Ser120, His275, and Asp247 (Figure S7).

The RPA1511 structure also revealed the presence of an additional electron density in the active site located close to the catalytic Ser114 (4.6 A) (Figure 7B-D). On the basis of the elongated linear shape, this density was interpreted as a molecule of polyethylene glycol PEG 3350 (modeled as dodecaethylene glycol), which was present in the crystallization solution. This ligand can be considered as a nonhydrolyzable PLA analogue and likely mimics a PLA molecule bound in the RPA1511 active site. Surface potential analysis of the RPA1511 structure revealed a narrow active site opening with an essentially neutral surface for the lid domain and active site cleft (Figure 7C). One end of the PEG 3350 ligand is buried in the RPA1511 active site between the side chains of Met215 (3.7-3.9 $\AA$ ) and Tyr144 (3.4-4.3 $\AA$ ) with the terminal OH-group positioned close to the side chain of Trp218 (4.2 $\mathrm{A}$ ) (Figure 7). The main part of the bound ligand is located in the alcohol binding site with the second end extending to solvent. The mode of ligand positioning in the active site cavity of RPA1511 suggests that this enzyme is likely to be able to perform both exo- and endoesterase cleavage of PLA.

\section{Potential Catalytic Mechanism of PLA Hydrolysis}

The three-dimensional arrangement of the catalytic triad residues of RPA1511 is similar to that of related $a / \beta$-hydrolases suggesting that this enzyme employs a classical Ser hydrolase mechanism for PLA hydrolysis. ${ }^{64}$ This is supported by the results of alanine replacement mutagenesis of both RPA1511 and ABO2449, which revealed that the catalytic triad residues are critical for their activity against both PLA and $a$-naphthyl propionate (Figure 8, $\mathrm{ABO} 2449, \mathrm{H} 275 \mathrm{~A}$, and D247A are not shown as they were found to be insoluble). On the basis of a classical Ser hydrolase mechanism, in RPA1511 the nucleophilic Ser114 is deprotonated by the His270-Asp242 general base and attacks the carbon atom of the substrate ester bond carbonyl group. The produced tetrahedral intermediate- 1 is stabilized by hydrogen bonds with the RPA1511 oxyanion hole which, according to the RPA1511 structure, appears to include the main chain NH groups of Ala115 and Ala140 (3.1 and 4.7 $\AA$ to Ser114, respectively). The tetrahedral intermediate- 1 then breaks down, by general acid catalysis, to a covalent acyl-enzyme intermediate with the polyester moiety attached to Ser114, whereas the imidazole group of His 270 transfers the proton of the serine hydroxyl to the leaving group producing lactic acid (or lactic acid oligomers in the case of endoesterase cleavage). The covalent enzyme intermediate is hydrolyzed by the nucleophilic attack of the catalytic water molecule activated by His 270 producing the regenerated enzyme and the second reaction product (the lactic acid monomer or oligomer). 


\section{Site-Directed Mutagenesis Identified Residues Important for PLA Hydrolysis}

To provide insight into the role of the RPA1511 and ABO2449 residues in the hydrolysis of polyester substrates, we performed site-directed mutagenesis (alanine replacement) of the active site residues. The mutated proteins were purified and analyzed for hydrolytic activity against two substrates, $a$-naphthyl propionate (Figure 8A,B) and emulsified PLA10 on agarose plates (Figure 8C,D). In addition to the catalytic triad residues, site-directed mutagenesis identified several other residues, which were important for the hydrolysis of both substrates including His113, Leu182, and Tyr198 in RPA1511 and Leu32 and Leu249 in ABO2449 (Figure 8). In the RPA1511 structure, the side chain of His113 is located close to the catalytic Ser114, whereas the side chains of Leu182 and Tyr198 are part of the alcohol-binding pocket suggesting that these residues contribute to binding of both monoester and polyester substrates. We also identified a number of mutant proteins retaining the wild-type or slightly reduced activity against both substrates (RPA1511: Y144A, F169A, L212A, R243A, and I245A; ABO2449: M144A, L163A, M183A, F219A, and P302R). Interestingly, RPA1511-V202A showed a significantly higher activity against PLA and lower activity toward $a$-naphthyl propionate compared to the wild type protein suggesting that the Val202 side chain might interfere with PLA binding.

Most importantly, site-directed mutagenesis revealed the residues that were essential for PLA hydrolysis but not required for activity against $a$-naphthyl propionate (Figure 8). In RPA1511, these residues include Thr48, Gln172, Arg181, Leu212, Met215, Trp218, Leu220, and Lys252, whereas Phe38 and Leu152 were identified in ABO2449 (Figure 8). In the RPA1511 structure, four of these residues (Thr48, Gln172, Met215, and Trp218) are in direct contact or close to the bound polyethylene glycol ligand (PLA analog) suggesting that these residues are likely to be involved in PLA binding. Although the other three residues (Arg181, Leu220, and Lys252) were not in direct contact with the bound PEG ligand, they might potentially contribute to the binding of longer PLA molecules. Thus, the active site of RPA1511 includes several hydrophobic, polar, and charged residues, which can establish hydrophobic or H-bond interactions with the PLA side chain methyl and carbonyl groups. Sequence analysis revealed that Leu212, Met215, Trp218, and Leu220 showed significant conservation and are present in many uncharacterized proteins. However, these residues could not be identified in the sequence of ABO2449, suggesting a different mode of PLA binding for this protein.

Analysis of the crystal structures of the PHB depolymerases from Penicillium funiculosum ${ }^{65}$ and Paucimonas lemoignei (PhaZ7 ${ }^{66}$ revealed the presence of conserved tryptophan residues in their active sites (Trp310 and Trp287, respectively), which appear to be involved in polymeric substrate binding. However, the role of these Trp residues in PHB hydrolysis has not yet been investigated. In contrast, no homologous Trp residues were found in the active sites of many carboxyl esterases and lipases, for which PLA degrading activity has not been reported (e.g., PDB codes 1I6W, 4LIP, 4X6U, 3GUU, 4CCW, 3I6Y). This suggests that the RPA1511 Trp218 and homologous Trp residues in the active sites of PHB depolymerases play an important role in the coordination and hydrolysis of the polyester substrate. We propose that for some $\alpha / \beta$-hydrolases the presence of similarly positioned Trp residues in the active sites might represent a structural motif for the potential hydrolytic 
activity against polyester substrates. Additional biochemical and structural studies are in progress to verify the role of conserved Trp residues in the active site of PLA depolymerases and to provide further insights into the molecular mechanisms of enzymatic hydrolysis of polyesters.

\section{CONCLUSIONS}

We have identified two highly active novel microbial carboxyl esterases ABO2449 and RPA1511 that can efficiently hydrolyze PLA and other polyesters as well as soluble monoester substrates. In contrast to proteinase $\mathrm{K}$, which is active against L-PLA, ${ }^{19}$ both ABO2449 and RPA1511 appear to be specific for D,L-PLA as they showed no activity against either L-PLA or D-PLA (Table 1). ABO2449 completely degraded both emulsified and solid PLA substrates within several hours or 2 days (over $90 \%$ conversion). The crystal structure of RPA1511 revealed the presence of a polyethylene glycol molecule bound in the active site close to the catalytic Ser114, likely mimicking the bound PLA substrate (Figure 7). The position of bound ligand in the RPA1511 active site and analysis of the PLA hydrolysis products suggest that this enzyme can perform both endo- and exoesterase cleavage of PLA. Using structure-based site-directed mutagenesis, we identified several residues of RPA1511 that were essential for PLA hydrolysis but not required for activity against a soluble monoester substrate. These residues represent a potential structural motif for PLA binding, and further characterization will help to narrow the search for novel PLA depolymerases based on sequence analysis.

PLA and its copolymers are man-made and thus not natural substrates for microbial esterases. PLA hydrolysis activity stems from enzyme promiscuity, which is important for the evolution of novel enzymes in nature and for biotechnological applications. ${ }^{67-69}$ Global genome and metagenome sequencing efforts generated millions of genes with unknown function. Enzymatic screening of uncharacterized proteins from sequenced genomes for hydrolytic activity against unusual polyester substrates is bound to reveal many new depolymerases with interesting properties for potential applications in plastics recycling, and provide additional sequence and structural features to narrowing the search for new activities.

\section{Supplementary Material}

Refer to Web version on PubMed Central for supplementary material.

\section{ACKNOWLEDGMENTS}

\footnotetext{
We are grateful to Dr. Toshiaki Nakajima-Kambe (University of Tsukuba, Ibaraki, Japan) for providing the PLA depolymerase clone PlaM4 as well as Bionolle polybutylene succinate and polybutylene succinate-co-adipate substrates; to Dr. Craig Criddle and Dr. Weimin Wu (Stanford University, California) for providing commercialgrade polymers; to Dr. Jeong Chan Joo and Dr. Yong Hwan Kim (Kwangwoon University, Seoul, Republic of Korea) for providing the D-lactic dehydrogenase clone D-LDH3; and to Dr. Timothy P. Bender (Department of Chemical Engineering and Applied Chemistry, University of Toronto) for helping with gel permeation chromatography analysis. This work was supported by the Government of Canada through Genome Canada and the Ontario Genomics Institute (2009-OGI-ABC-1405), Ontario Research Fund (ORF-GL2-01-004), the NSERC Strategic Network grant IBN, and by the United States Department of Energy, Office of Biological and Environmental Research, under Contract No. DE-AC02-06CH11357 (to A.J.).
} 


\section{REFERENCES}

(1). Thompson RC; Moore CJ; vom Saal FS; Swan SH Plastics, the environment and human health: current consensus and future trends. Philos. Trans. R. Soc., B 2009, 364 (1526), 2153-2166.

(2). de Clippel F; Dusselier M; Van Rompaey R; Vanelderen P; Dijkmans J; Makshina E; Giebeler L; Oswald S; Baron GV; Denayer JF; Pescarmona PP; Jacobs PA; Sels BF Fast and selective sugar conversion to alkyl lactate and lactic acid with bifunctional carbon-silica catalysts. J. Am. Chem. Soc 2012, 134 (24), 10089-10101. [PubMed: 22550936]

(3). Plastics-the Facts 2015; PlasticsEurope Market Research Group (PEMRG), 2015 http:// www.plasticseurope.org/cust/documentrequest.aspx?DocID=65435 (accessed April 11, 2016).

(4). Law KL; Thompson RC, Oceans. Microplastics in the seas. Science 2014, 345 (6193), 144-145. [PubMed: 25013051]

(5). Ragauskas AJ; Williams CK; Davison BH; Britovsek G; Cairney J; Eckert CA; Frederick WJ Jr.; Hallett JP; Leak DJ; Liotta CL; Mielenz JR; Murphy R; Templer R; Tschaplinski T The path forward for biofuels and biomaterials. Science 2006, 311 (5760), 484-489. [PubMed: 16439654]

(6). Shah AA; Hasan F; Hameed A; Ahmed S Biological degradation of plastics: a comprehensive review. Biotechnol. Adv. 2008, 26 (3), 246-265. [PubMed: 18337047]

(7). Gross RA; Kalra B Biodegradable polymers for the environment. Science 2002, 297 (5582), 803807. [PubMed: 12161646]

(8). Álvarez-Chávez CR; Edwards S; Moure-Eraso R; Geiser K Sustainability of bio-based plastics: general comparative analysis and recommendations for improvement. J. Cleaner Prod 2012, 23 (1), 47-56.

(9). Niaounakis M Biopolymers Reuse, Recycling, and Disposal; Elsevier Inc.: Amsterdam, 2013; p 413.

(10). Madhavan Nampoothiri K; Nair NR; John RP An overview of the recent developments in polylactide (PLA) research. Bioresour. Technol. 2010, 101 (22), 8493-8501. [PubMed: 20630747]

(11). Södergård A; Stolt M Properties of lactic acid based polymers and their correlation with composition. Prog. Polym. Sci 2002, 27 (6), 1123-1163.

(12). Albertsson AC; Edlund U; Stridsberg K In Controlled Ring-Opening Polymerization of Lactones and Lactides, Macromolecular Symposia, 2000; Wiley Online Library, 2000; pp 39-46.

(13). Kawai F; Nakadai K; Nishioka E; Nakajima H; Ohara H; Masaki K; Iefuji H Different enantioselectivity of two types of poly (lactic acid) depolymerases toward poly (L-lactic acid) and poly (D-lactic acid). Polym. Degrad. Stab 2011, 96 (7), 1342-1348.

(14). Pranamuda H; Tokiwa Y; Tanaka H Polylactide Degradation by an Amycolatopsis sp. Appl. Environ. Microbiol 1997, 63 (4), 1637-1640. [PubMed: 16535586]

(15). Jarerat A; Pranamuda H; Tokiwa Y Poly (L-lactide)-degrading activity in various actinomycetes. Macromol. Biosci 2002, 2 (9), 420-428.

(16). kHitomi M; Sanda F; Endo T Reversible crosslinking-decrosslinking of polymers having bicyclo orthoester moieties in the side chains. Macromol. Chem. Phys 1999, 200 (6), 1268-1273.

(17). Kobayashi S; Uyama H; Takamoto T Lipase-catalyzed degradation of polyesters in organic solvents. A new methodology of polymer recycling using enzyme as catalyst. Biomacromolecules 2000, 1 (1), 3-5. [PubMed: 11709839]

(18). Matsumura S Enzyme-Catalyzed Synthesis and Chemical Recycling of Polyesters. Macromol. Biosci 2002, 2 (3), 105-126.

(19). Williams D Enzymic hydrolysis of polylactic acid. Engineering in Medicine 1981, 10 (1), 5-7.

(20). Fukuzaki H; Yoshida M; Asano M; Kumakura M Synthesis of copoly (D, L-lactic acid) with relatively low molecular weight and in vitro degradation. Eur. Polym. J 1989, 25 (10), 1019_ 1026.

(21). Akutsu Y; Nakajima-Kambe T; Nomura N; Nakahara T Purification and Properties of a Polyester Polyurethane-Degrading Enzyme from Comamonas acidovorans TB-35. Appl. Environ. Microbiol 1998, 64 (1), 62-67. [PubMed: 16349494] 
(22). Tokiwa Y; Jarerat A Biodegradation of poly(L-lactide). Biotechnol. Lett 2004, 26 (10), 771-777. [PubMed: 15274245]

(23). Akutsu-Shigeno Y; Teeraphatpornchai T; Teamtisong K; Nomura N; Uchiyama H; Nakahara T; Nakajima-Kambe T Cloning and sequencing of a poly(DL-lactic acid) depolymerase gene from Paenibacillus amylolyticus strain TB-13 and its functional expression in Escherichia coli. Appl. Environ. Microbiol 2003, 69 (5), 2498-2504. [PubMed: 12732514]

(24). Oda Y; Yonetsu A; Urakami T; Tonomura K Degradation of polylactide by commercial proteases. J. Polym. Environ 2000, 8 (1), 29-32.

(25). Hoshino A; Isono Y Degradation of aliphatic polyester films by commercially available lipases with special reference to rapid and complete degradation of poly(L-lactide) film by lipase PL derived from Alcaligenes sp. Biodegradation 2002, 13 (2), 141-147. [PubMed: 12449316]

(26). Masaki K; Kamini NR; Ikeda H; Iefuji H Cutinase-like enzyme from the yeast Cryptococcus sp. strain S-2 hydrolyzes polylactic acid and other biodegradable plastics. Appl. Environ. Microbiol 2005, 71 (11), 7548-7550. [PubMed: 16269800]

(27). Pranamuda H; Tsuchii A; Tokiwa Y Poly (L-lactide)-Degrading Enzyme Produced by Amycolatopsis sp. Macromol. Biosci 2001, 1 (1), 25-29.

(28). Nakamura K; Tomita T; Abe N; Kamio Y Purification and characterization of an extracellular poly(L-lactic acid) depolymerase from a soil isolate, Amycolatopsis sp. strain K104-1. Appl. Environ. Microbiol 2001, 67 (1), 345-353. [PubMed: 11133465]

(29). Mayumi D; Akutsu-Shigeno Y; Uchiyama H; Nomura N; Nakajima-Kambe T Identification and characterization of novel poly(DL-lactic acid) depolymerases from metagenome. Appl. Microbiol. Biotechnol 2008, 79 (5), 743-750. [PubMed: 18461319]

(30). Maeda H; Yamagata Y; Abe K; Hasegawa F; Machida M; Ishioka R; Gomi K; Nakajima T Purification and characterization of a biodegradable plastic-degrading enzyme from Aspergillus oryzae. Appl. Microbiol. Biotechnol 2005, 67 (6), 778-788. [PubMed: 15968570]

(31). Tchigvintsev A; Tran H; Popovic A; Kovacic F; Brown G; Flick R; Hajighasemi M; Egorova O; Somody JC; Tchigvintsev D; et al. The environment shapes microbial enzymes: five cold-active and salt-resistant carboxylesterases from marine metagenomes. Appl. Microbiol. Biotechnol 2015, 99 (5), 2165-2178. [PubMed: 25194841]

(32). Numata K; Finne-Wistrand A; Albertsson A-C; Doi Y; Abe H Enzymatic degradation of monolayer for poly (lactide) revealed by real-time atomic force microscopy: effects of stereochemical structure, molecular weight, and molecular branches on hydrolysis rates. Biomacromolecules 2008, 9 (8), 2180-2185. [PubMed: 18636774]

(33). Tsuji H Polylactides In Biopolymers, Polyesters III-Applications and Commercial Products; Doi Y, Steinbüchel A, Eds.; Wiley-Blackwell: Weinheim, Gernamy, 2002; Vol. 4, pp 129-177.

(34). Numata K; Srivastava RK; Finne-Wistrand A; Albertsson A-C; Doi Y; Abe H Branched poly (lactide) synthesized by enzymatic polymerization: Effects of molecular branches and stereochemistry on enzymatic degradation and alkaline hydrolysis. Biomacromolecules 2007, 8 (10), 3115-3125. [PubMed: 17722879]

(35). Yamashita K; Kikkawa Y; Kurokawa K; Doi Y Enzymatic degradation of poly (L-lactide) film by proteinase $\mathrm{K}$ : quartz crystal microbalance and atomic force microscopy study. Biomacromolecules 2005, 6 (2), 850-857. [PubMed: 15762651]

(36). Reeve MS; McCarthy SP; Downey MJ; Gross RA Polylactide stereochemistry: effect on enzymic degradability. Macromolecules 1994, 27 (3), 825-831.

(37). Gonzalez CF; Proudfoot M; Brown G; Korniyenko Y; Mori H; Savchenko AV; Yakunin AF Molecular basis of formaldehyde detoxification. Characterization of two S-formylglutathione hydrolases from Escherichia coli, FrmB and YeiG. J. Biol. Chem 2006, 281 (20), 14514-14522. [PubMed: 16567800]

(38). Sievers F; Wilm A; Dineen D; Gibson TJ; Karplus K; Li W; Lopez R; McWilliam H; Remmert M; Söding J; et al. Fast, scalable generation of high-quality protein multiple sequence alignments using Clustal Omega. Mol. Syst. Biol 2011, 7 (1), 1-6.

(39). Tamura K; Stecher G; Peterson D; Filipski A; Kumar S MEGA6: Molecular Evolutionary Genetics Analysis version 6.0. Mol. Biol. Evol 2013, 30 (12), 2725-2729. [PubMed: 24132122] 
(40). Teeraphatpornchai T; Nakajima-Kambe T; Shigeno-Akutsu Y; Nakayama M; Nomura N; Nakahara T; Uchiyama H Isolation and characterization of a bacterium that degrades various polyester-based biodegradable plastics. Biotechnol. Lett 2003, 25 (1), 23-28. [PubMed: 12882301]

(41). Babson AL; Phillips G A rapid colorimetric assay for serum lactic dehyurogenase. Clin. Chim. Acta 1965, 12 (2), 210-215. [PubMed: 5856284]

(42). Jun C; Sa YS; Gu S-A; Joo JC; Kim S; Kim K-J; Kim YH Discovery and characterization of a thermostable d-lactate dehydrogenase from Lactobacillus jensenii through genome mining. Process Biochem. 2013, 48 (1), 109-117.

(43). Codari F; Moscatelli D; Storti G; Morbidelli M Characterization of Low-Molecular-Weight PLA using HPLC. Macromol. Mater. Eng 2010, 295 (1), 58-66.

(44). Vedadi M; Niesen FH; Allali-Hassani A; Fedorov OY; Finerty PJ Jr.; Wasney GA; Yeung R; Arrowsmith C; Ball LJ; Berglund H; Hui R; Marsden BD; Nordlund P; Sundstrom M; Weigelt J; Edwards AM Chemical screening methods to identify ligands that promote protein stability, protein crystallization, and structure determination. Proc. Natl. Acad. Sci. U. S. A 2006, 103 (43), 15835-15840. [PubMed: 17035505]

(45). Rosenbaum G; Alkire RW; Evans G; Rotella FJ; Lazarski K; Zhang R-G; Ginell SL; Duke N; Naday I; Lazarz J; et al. The Structural Biology Center 19ID undulator beamline: facility specifications and protein crystallographic results. J. Synchrotron Radiat 2006, 13 (1), 30-45. [PubMed: 16371706]

(46). Minor W; Cymborowski M; Otwinowski Z; Chruszcz M HKL-3000: the integration of data reduction and structure solution-from diffraction images to an initial model in minutes. Acta Crystallogr., Sect. D: Biol. Crystallogr 2006, 62 (8), 859-866. [PubMed: 16855301]

(47). Emsley P; Lohkamp B; Scott WG; Cowtan K Features and development of Coot. Acta Crystallogr., Sect. D: Biol. Crystallogr 2010, 66 (4), 486-501. [PubMed: 20383002]

(48). Adams PD; Afonine PV; Bunkóczi G; Chen VB; Davis IW; Echols N; Headd JJ; Hung L-W; Kapral GJ; Grosse-Kunstleve RW; et al. PHENIX: a comprehensive Python-based system for macromolecular structure solution. Acta Crystallogr., Sect. D: Biol. Crystallogr 2010, 66 (2), 213-221. [PubMed: 20124702]

(49). Murshudov GN; Vagin AA; Dodson EJ Refinement of macromolecular structures by the maximum-likelihood method. Acta Crystallogr., Sect. D: Biol. Crystallogr 1997, 53 (3), 240 255. [PubMed: 15299926]

(50). Dolinsky TJ; Czodrowski P; Li H; Nielsen JE; Jensen JH; Klebe G; Baker NA PDB2PQR: expanding and upgrading automated preparation of biomolecular structures for molecular simulations. Nucleic Acids Res. 2007, 35, W522-W525. [PubMed: 17488841]

(51). Baker NA; Sept D; Joseph S; Holst MJ; McCammon JA Electrostatics of nanosystems: application to microtubules and the ribosome. Proc. Natl. Acad. Sci. U. S. A 2001, 98 (18), 10037-10041. [PubMed: 11517324]

(52). Cai H; Dave V; Gross RA; McCarthy SP Effects of physical aging, crystallinity, and orientation on the enzymatic degradation of poly (lactic acid). J. Polym. Sci., Part B: Polym. Phys 1996, 34 (16), 2701-2708.

(53). Mao H; Jiang H; Su T; Wang Z Purification and characterization of two extracellular polyhydroxyalkanoate depolymerases from Pseudomonas mendocina. Biotechnol. Lett 2013, 35 (11), 1919-1924. [PubMed: 23881326]

(54). Lenfant N; Hotelier T; Velluet E; Bourne Y; Marchot P; Chatonnet A ESTHER, the database of the $a / \beta$-hydrolase fold superfamily of proteins: tools to explore diversity of functions. Nucleic Acids Res. 2013, 41, D423. [PubMed: 23193256]

(55). Arpigny JL; Jaeger K-E Bacterial lipolytic enzymes: classification and properties. Biochem. J 1999, 343 (1), 177-183. [PubMed: 10493927]

(56). Huisman GW; Wonink E; Meima R; Kazemier B; Terpstra P; Witholt B Metabolism of poly(3hydroxyalkanoates) (PHAs) by Pseudomonas oleovorans. Identification and sequences of genes and function of the encoded proteins in the synthesis and degradation of PHA. J. Biol. Chem 1991, 266 (4), 2191-2198. [PubMed: 1989978] 
(57). Tsuji H; Miyauchi S Poly (L-lactide): VI Effects of crystallinity on enzymatic hydrolysis of poly (L-lactide) without free amorphous region. Polym. Degrad. Stab 2001, 71 (3), 415-424.

(58). Hocking PJ; Marchessault RH; Timmins MR; Lenz RW; Fuller RC Enzymatic degradation of single crystals of bacterial and synthetic poly ( $\beta$-hydroxybutyrate). Macromolecules 1996, 29 (7), 2472-2478.

(59). Li F; Wang S; Liu W; Chen G Purification and characterization of poly(L-lactic acid)-degrading enzymes from Amycolatopsis orientalis ssp. orientalis. FEMS Microbiol. Lett 2008, 282 (1), 52 58. [PubMed: 18355279]

(60). Yakimov MM; Golyshin PN; Lang S; Moore ER; Abraham W-R; Lünsdorf H; Timmis KN Alcanivorax borkumensis gen. nov., sp. nov., a new, hydrocarbon-degrading and surfactantproducing marine bacterium. Int. J. Syst. Bacteriol 1998, 48 (2), 339-348. [PubMed: 9731272]

(61). Nardini M; Dijkstra BW $a / \beta$ Hydrolase fold enzymes: the family keeps growing. Curr. Opin. Struct. Biol 1999, 9 (6), 732-737. [PubMed: 10607665]

(62). Holm L; Rosenström P Dali server: conservation mapping in 3D. Nucleic Acids Res. 2010, 38, W545-W549. [PubMed: 20457744]

(63). Kelley LA; Mezulis S; Yates CM; Wass MN; Sternberg MJ The Phyre2 web portal for protein modeling, prediction and analysis. Nat. Protoc 2015, 10 (6), 845-858. [PubMed: 25950237]

(64). Ollis DL; Carr PD Alpha/beta hydrolase fold: an update. Protein Pept. Lett 2009, 16 (10), 11371148. [PubMed: 19508187]

(65). Hisano T; Kasuya K; Tezuka Y; Ishii N; Kobayashi T; Shiraki M; Oroudjev E; Hansma H; Iwata T; Doi Y; Saito T; Miki K The crystal structure of polyhydroxybutyrate depolymerase from Penicillium funiculosum provides insights into the recognition and degradation of biopolyesters. J. Mol. Biol 2006, 356 (4), 993-1004. [PubMed: 16405909]

(66). Papageorgiou AC; Hermawan S; Singh CB; Jendrossek D Structural basis of poly(3hydroxybutyrate) hydrolysis by PhaZ7 depolymerase from Paucimonas lemoignei. J. Mol. Biol 2008, 382 (5), 1184-1194. [PubMed: 18706425]

(67). Tawfik OK; Tawfik DS Enzyme promiscuity: a mechanistic and evolutionary perspective. Annu. Rev. Biochem 2010, 79, 471-505. [PubMed: 20235827]

(68). Pandya C; Farelli JD; Dunaway-Mariano D; Allen KN Enzyme promiscuity: engine of evolutionary innovation. J. Biol. Chem 2014, 289 (44), 30229-30236. [PubMed: 25210039]

(69). Copley SD An evolutionary biochemist's perspective on promiscuity. Trends Biochem. Sci 2015, 40 (2), 72-78. [PubMed: 25573004] 


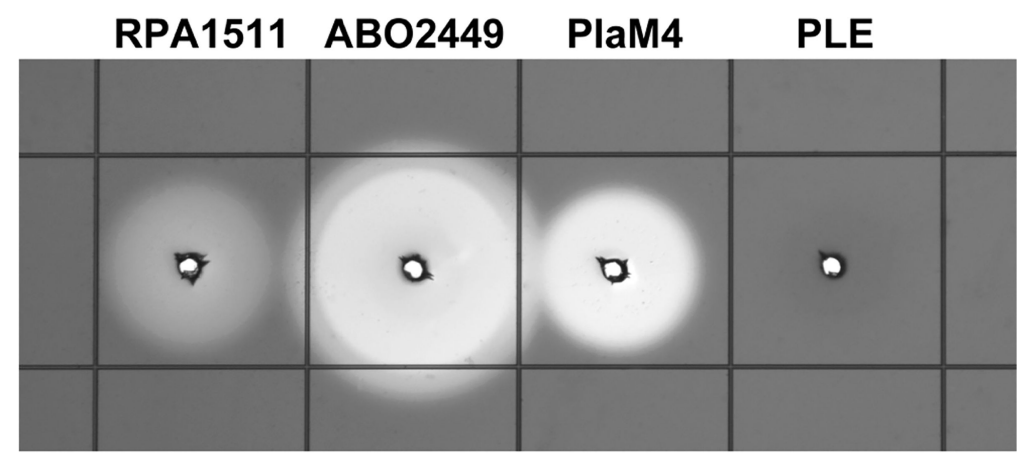

Figure 1.

Hydrolytic activity of purified RPA1511 and ABO2449 against emulsified PLA. Solid phase agarose gel-based PLA depolymerase assay with emulsified PLA10 as substrate showing the formation of a clear zone (a halo) around the wells (shown against a white background). Agarose (1.5\%) contained $0.2 \%$ emulsified PLA10 in $50 \mathrm{mM}$ Tris- $\mathrm{HCl}$ (pH 8.0). The wells were loaded with $50 \mu \mathrm{g}$ of purified protein (RPA1511, ABO2449, PlaM4, or porcine liver esterase, PLE) and incubated at $30^{\circ} \mathrm{C}$ for $72 \mathrm{~h}$. PlaM4 and PLE were used as positive and negative controls, respectively. 

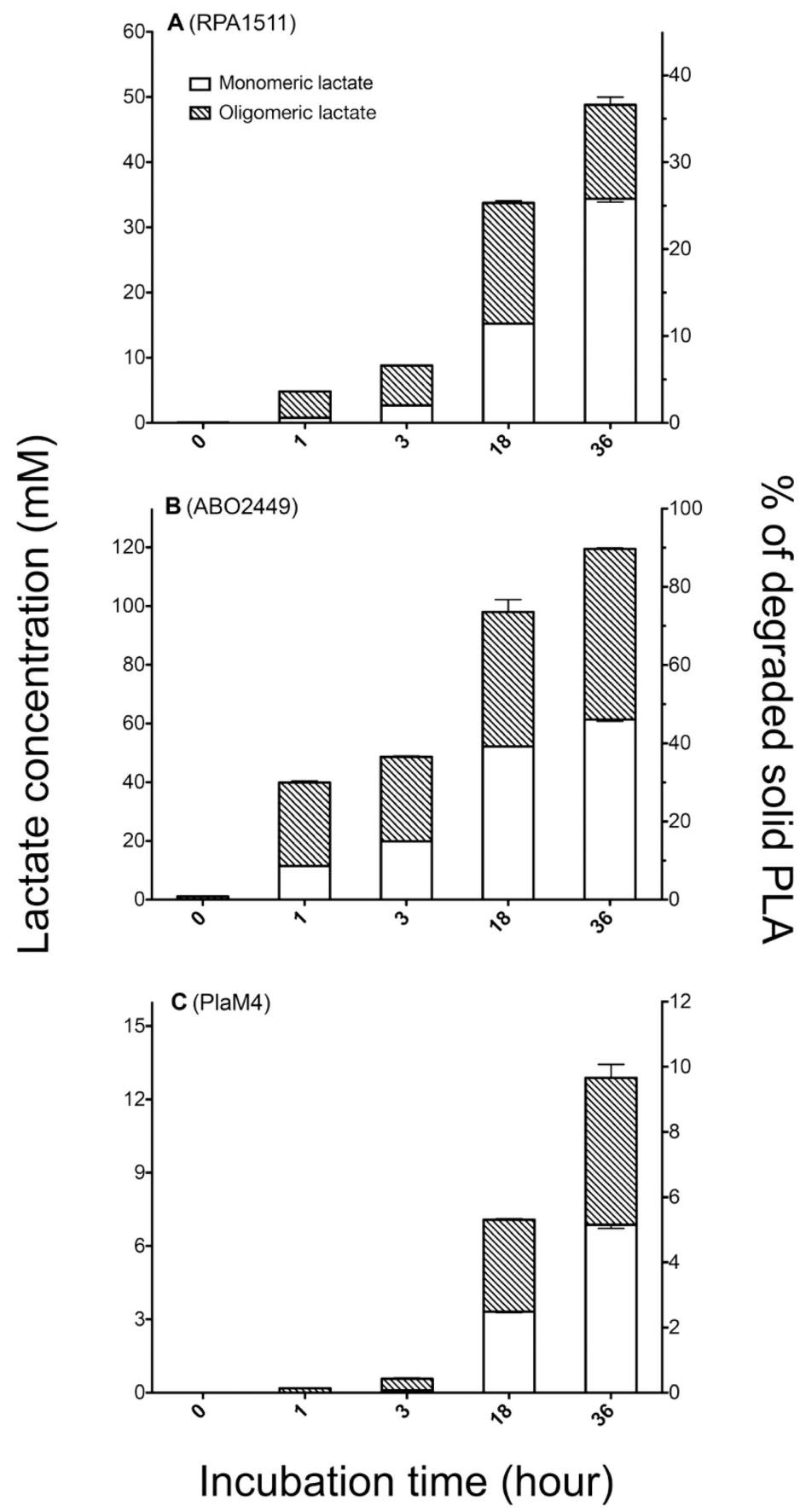

Figure 2.

Production of lactic acid from solid PLA10 by purified RPA1511, ABO2449, and PlaM4. The reaction mixtures $(1 \mathrm{~mL})$ contained solid PLA10 powder $(12 \mathrm{mg})$ in $0.4 \mathrm{M}$ Tris-HCl ( $\mathrm{pH}$ 8.0) and $50 \mu \mathrm{g}$ of purified enzyme (and 0.1\% (w/v) Plysurf A210G for ABO2449). Samples were clarified using centrifugal filters (MWCO $10 \mathrm{kDa}$ ), and monomeric lactic acid was analyzed using a lactate dehydrogenase assay. For the analysis of total lactic acid (monomeric and oligomeric) in flow-through fractions, aliquots were treated with $10 \mathrm{M}$ $\mathrm{NaOH}\left(95^{\circ} \mathrm{C}, 5 \mathrm{~min}\right)$ before lactate dehydrogenase assays. 


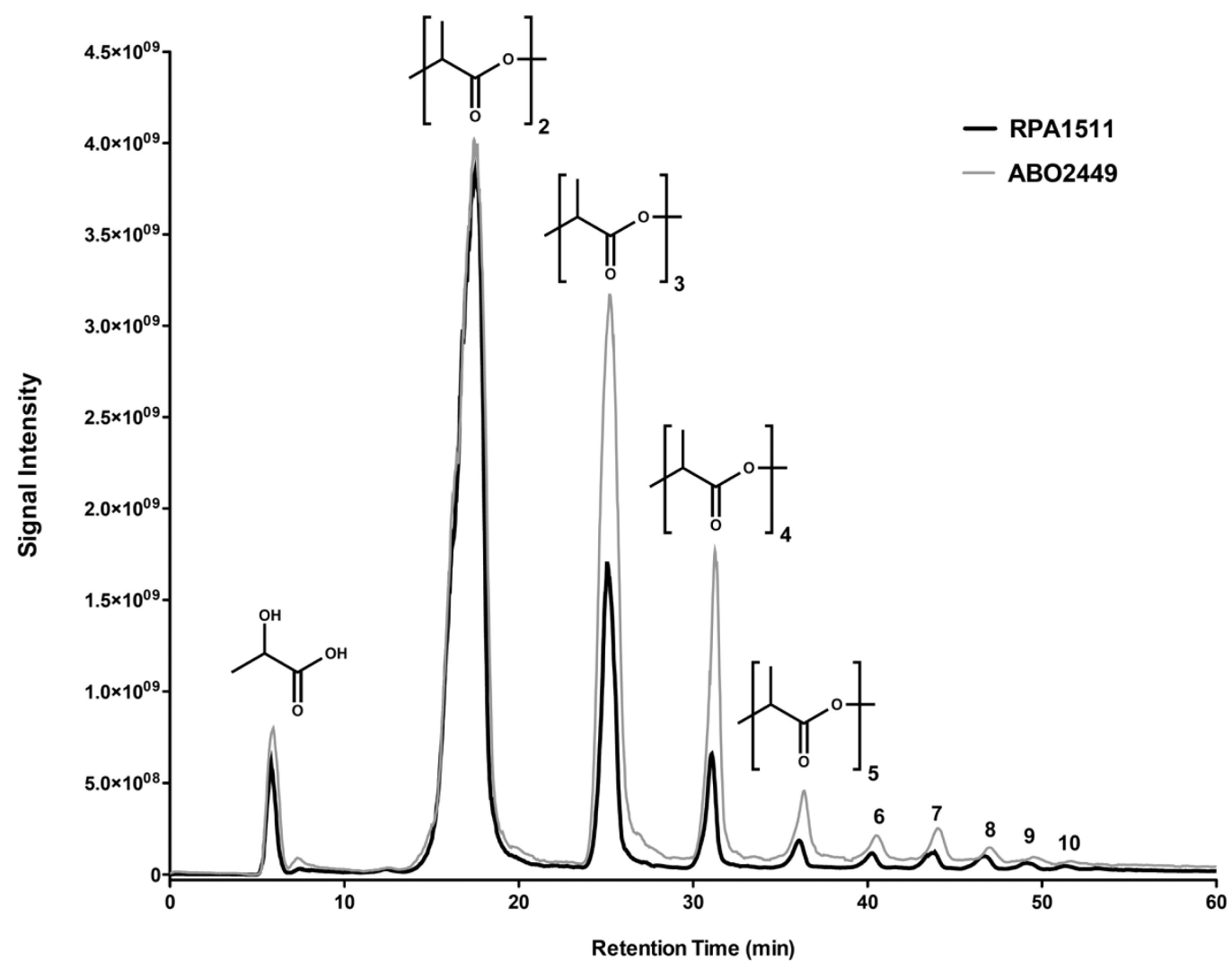

Figure 3.

LC-MS analysis of reaction products of solid PLA hydrolysis by purified RPA1511 and ABO2449. Reaction mixtures (1.0 mL) contained 0.4 M Tris-HCl (pH 8.0), solid PLA10 (20 $\mathrm{mg})$, and enzyme $(50 \mu \mathrm{g})$. Samples were collected after $\mathrm{O} / \mathrm{N}$ incubation at $35^{\circ} \mathrm{C}$, filtered by centrifugation, and analyzed by LC-MS as described in the Experimental Section. Each peak is labeled with a number representing the oligomeric state of these polyester species. 


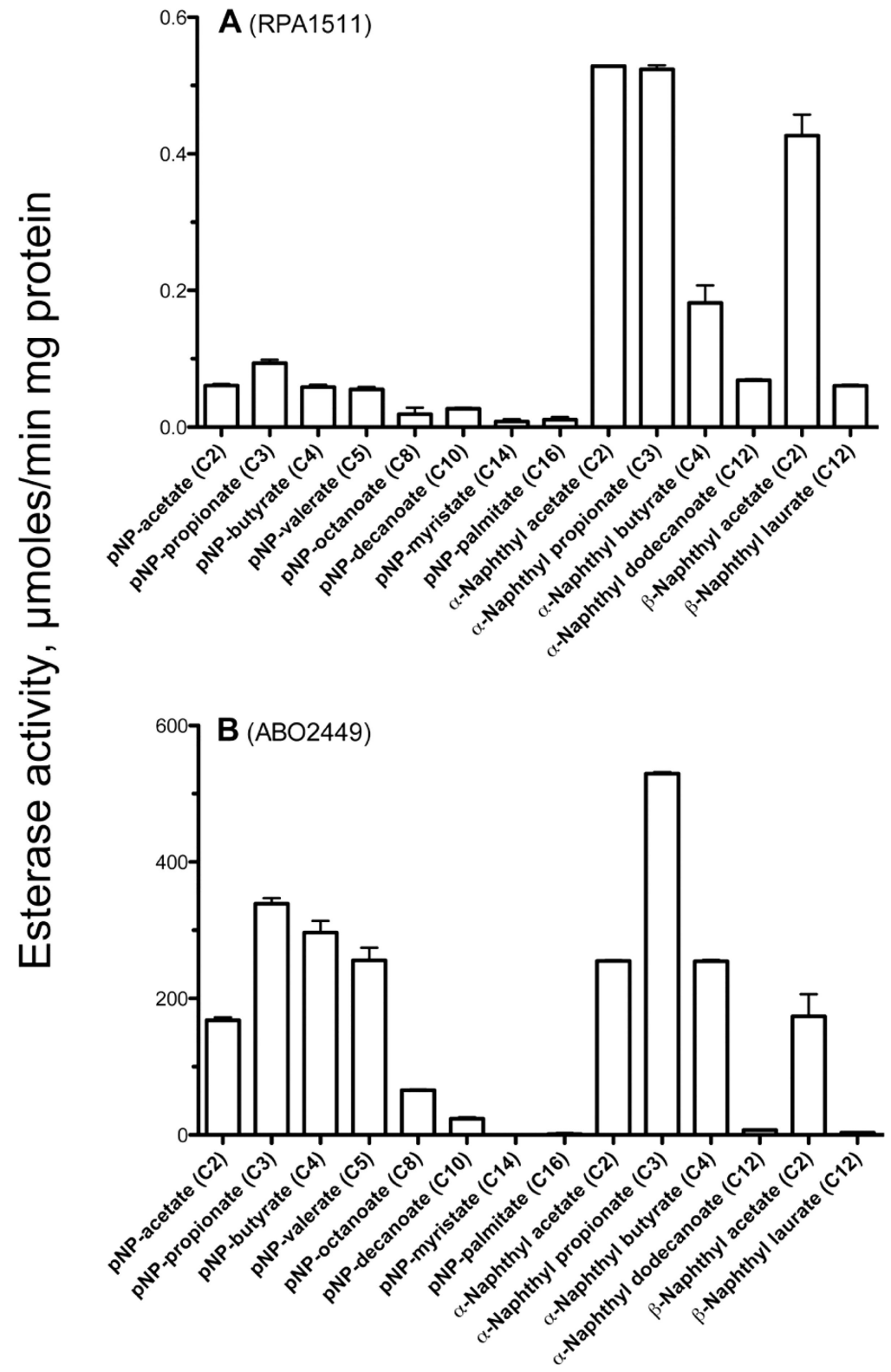

Figure 4.

Activity of RPA1511 and ABO2449 against model esterase substrates. The reaction mixtures $(200 \mu \mathrm{L})$ contained $0.5 \mathrm{mM} p \mathrm{NP}$ - or $1.5 \mathrm{mM}$ naphthyl ester substrates, and (A) 10 $\mu \mathrm{g}$ of RPA1511 or (B) $0.5 \mu \mathrm{g}$ of ABO2449. Experimental conditions were as described in the Experimental Section. Results are means \pm SD from at least two independent determinations. 


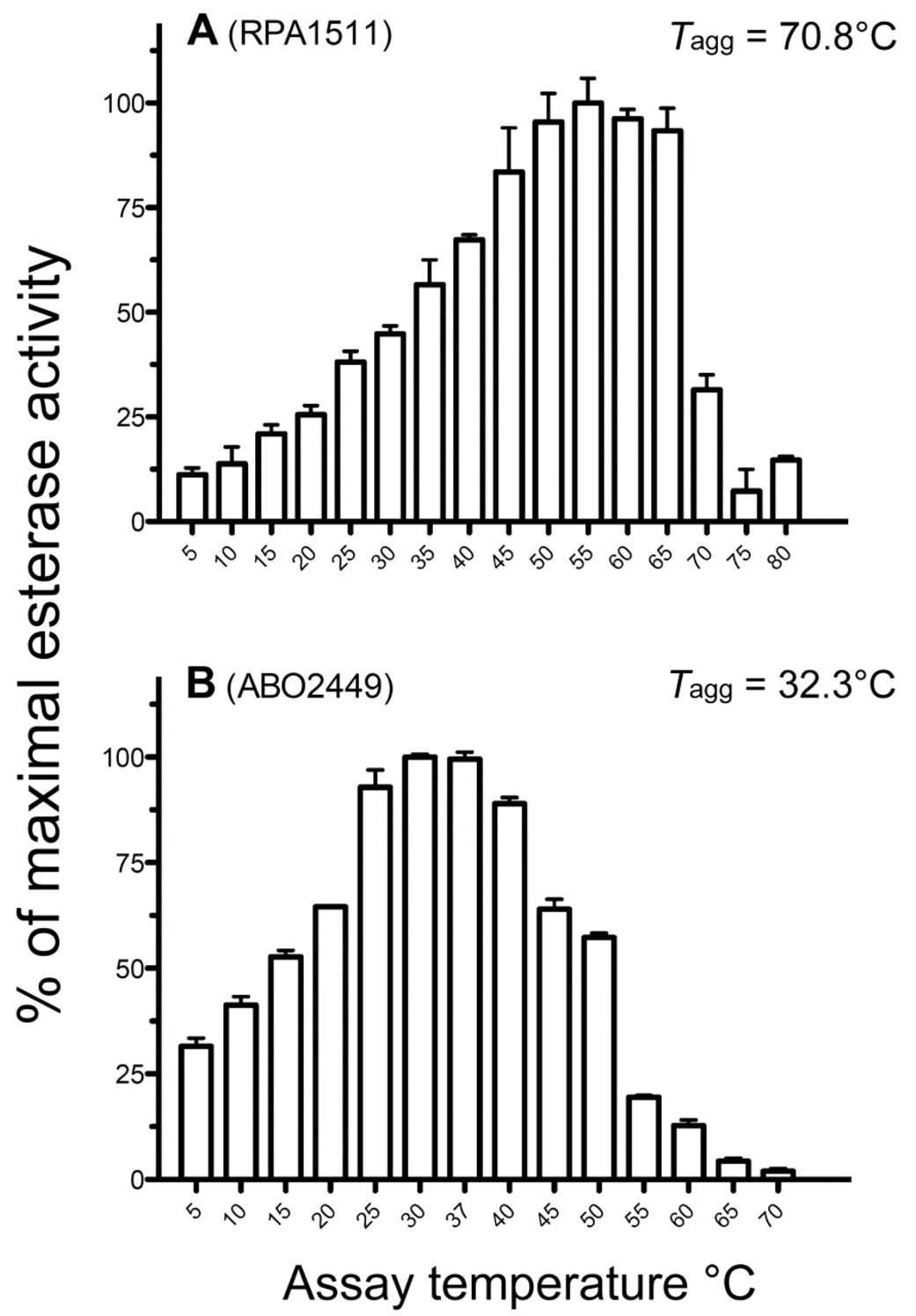

Figure 5.

Effect of temperature on esterase activity of (A) RPA1511 and (B) ABO2449. Esterase activity of purified proteins was measured at different temperatures using $a$-naphthyl propionate $(1.5 \mathrm{mM})$ as substrate and (A) $10 \mu \mathrm{g}$ of RPA1511 or (B) $0.5 \mu \mathrm{g}$ of ABO2449. Results are means \pm SD from at least two independent determinations. 


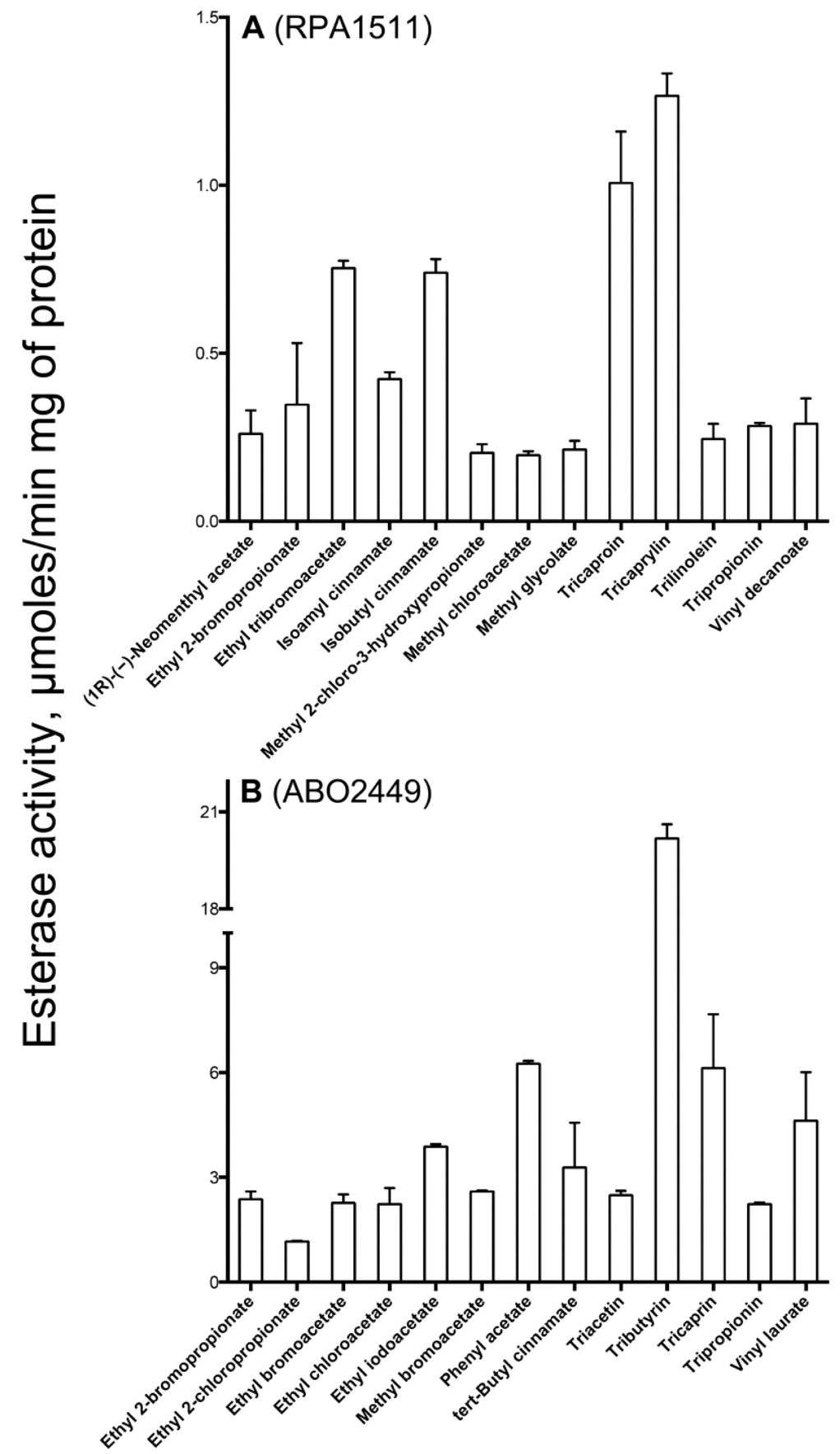

Figure 6.

Substrate profiles for (A) RPA1511 and (B) ABO2449 against soluble monoester substrates. Esterase activity of purified proteins was measured against a library of 86 soluble monoester substrates, and substrates supporting significant activity are shown on the graphs. 

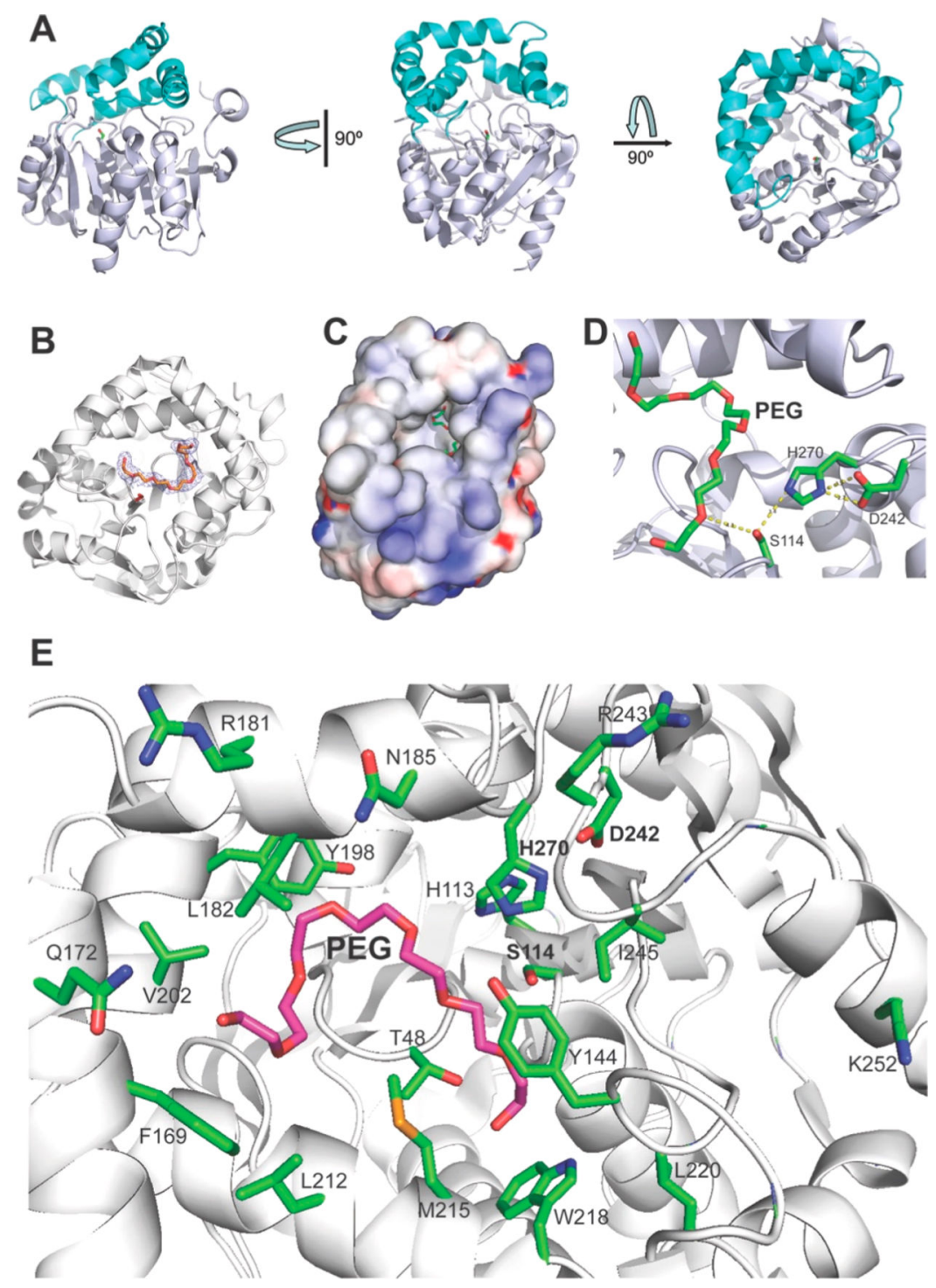

Figure 7.

Crystal structure of RPA1511: overall fold and catalytic triad. (A) Overall structure of the RPA1511 protomer shown in three views related by a $90^{\circ}$ rotation. The protein core domain is shown in gray, whereas the lid domain is colored in cyan. The position of the active site is indicated by the side chain of the catalytic Ser114. (B) RPA1511 protomer with bound PEG 3350 (dodecaethylene glycol, shown as sticks). $2 F O-F c$ map contoured at $1.0 \sigma$ displayed (shown as a blue mesh) around the dodecaethylene glycol molecule (colored in orange). (C) Surface presentation of the RPA1511 protomer revealing the entrance into the active site with bound PEG 3350 (shown as green sticks). Electrostatic potential mapped onto the solvent accessible protein surface with red color representing potential below $5 \mathrm{kT}$, blue above $5 \mathrm{kT}$, and white as neutral. (D) Close-up view of the dodecaethylene glycol molecule (PEG 3350) bound close to the catalytic triad Ser114, His270, and Asp242 (shown as sticks along the protein ribbon colored in gray). (E) Close-up view of the RPA1511 active site with bound PEG 3350. The protein ribbon is colored in gray with amino acid side chains shown 
as sticks and carbon atoms colored in green. The bound PEG 3350 molecule is shown as sticks with the carbon atoms colored in magenta. 


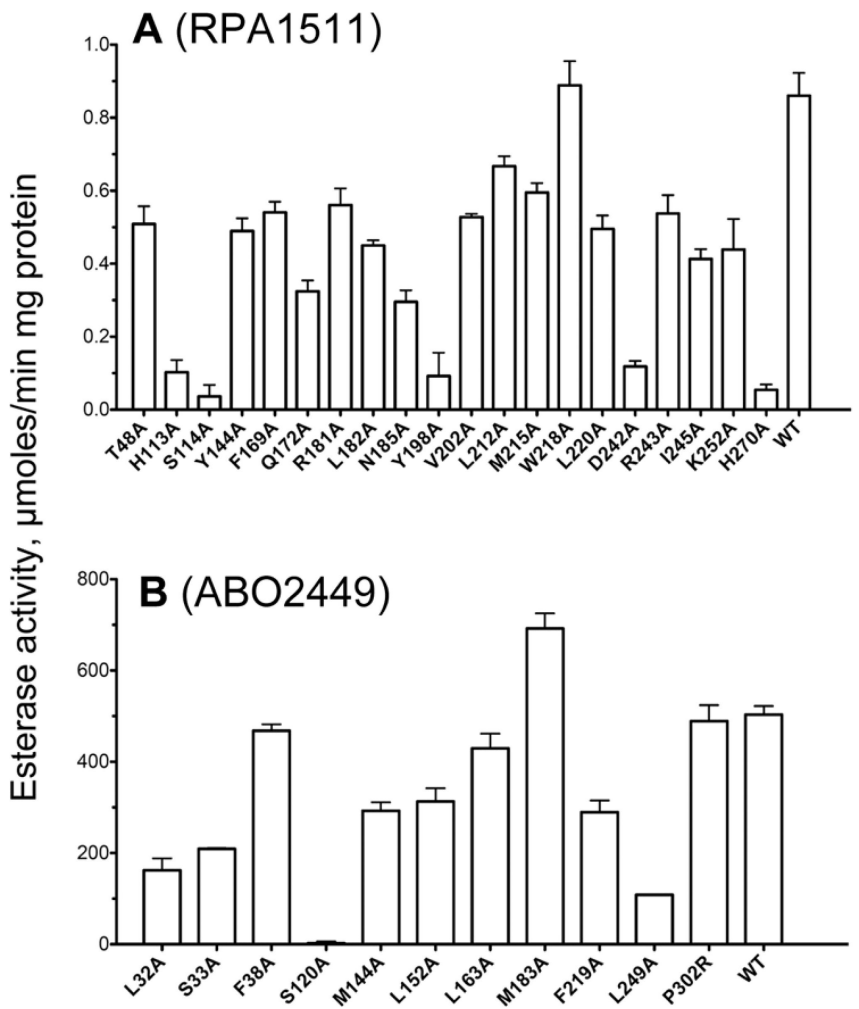

\section{C (RPA1511)}

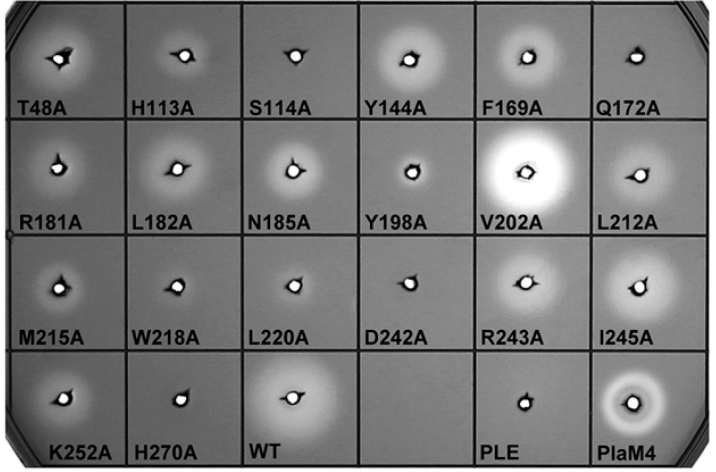

D (ABO2449)

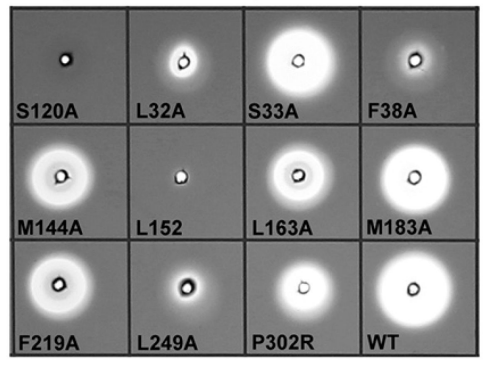

Figure 8.

Site-directed mutagenesis of RPA1511 and ABO2449: esterase activity of purified proteins. Enzymatic activity of the purified wild type (WT) and mutant proteins was measured using $a$-naphthyl propionate $\left(1.5 \mathrm{mM}, 15 \mathrm{~min}\right.$ incubation at $30^{\circ} \mathrm{C}$; panels A and B) or PLA10 (24 $\mathrm{h}$ incubation at $30^{\circ} \mathrm{C}$; panels $\mathrm{C}$ and $\left.\mathrm{D}\right)$ as substrates. The reaction mixtures contained: RPA1511, (A) $10 \mu \mathrm{g}$ or (C) $50 \mu \mathrm{g}$; ABO2449, (B) $0.5 \mu \mathrm{g}$ or (D) $50 \mu \mathrm{g}$. 
Table 1.

Hydrolytic Activity $^{a}$ of Purified RPA1511 and ABO2449 against Various Polyesters

\begin{tabular}{|c|c|c|c|}
\hline substrate & RPA1511 & ABO2449 & PlaM4 \\
\hline (1) Poly(D,L-lactide) $M_{\mathrm{w}} 2 \mathrm{~K}$ (PLA2) & + & + & + \\
\hline (2) Poly(D,L-lactide) $M_{\mathrm{w}} 10 \mathrm{~K}$ (PLA10) & + & + & + \\
\hline (3) Poly(D,L-lactide) $M_{\mathrm{w}} 18 \mathrm{~K}$ (PLA18) & + & + & + \\
\hline (4) Poly(D,L-lactide) $M_{\mathrm{w}} 70 \mathrm{~K}(\mathrm{PLA} 70)$ & + & + & + \\
\hline (5) Poly(L-lactide) $M_{\mathrm{w}} 40 \mathrm{~K}$ (PLLA40) & - & - & - \\
\hline (6) Poly(D-lactide) $M_{\mathrm{w}} 12 \mathrm{~K}$ (PDLA12) & - & - & - \\
\hline (7) Poly(D-lactide) $M_{\mathrm{W}} 124 \mathrm{~K}(\mathrm{PDLA} 124)^{b}$ & - & - & - \\
\hline (8) Poly(D,L-lactide) $M_{\mathrm{w}} 10 \mathrm{~K}\left(\mathrm{PLA} 10_{\mathrm{ac}}\right)$, decanoyl-capped acid end & + & + & + \\
\hline (9) Poly(D,L-lactide) $M_{\mathrm{w}} 10 \mathrm{~K}\left(\mathrm{PLA}_{10}\right)$, decanoyl-capped alcohol end & + & + & + \\
\hline (10) Poly(D,L-lactide) $M_{\mathrm{w}} 10 \mathrm{~K}\left(\mathrm{PLA} 10_{\mathrm{di}}\right)$, didecanoyl-end-capped & + & + & + \\
\hline (11) Ingeo PLA6400 & - & + & - \\
\hline (12) Ingeo PLA4032 & - & + & - \\
\hline (13) Poly(D,L-lactide-co-glycolide) & + & + & + \\
\hline (14) Poly[( $R$ )-3-hydroxybutyric acid $]$ & - & - & - \\
\hline (15) Poly(3-hydroxybutyric acid-co-3-hydroxyvaleric acid) & - & + & + \\
\hline (16) Polycaprolactone $M_{\mathrm{w}} 10 \mathrm{~K}$ (PCL10) & + & + & + \\
\hline (17) Polycaprolactone $M_{\mathrm{w}} 45 \mathrm{~K}$ (PCL45) & + & + & + \\
\hline (18) Polycaprolactone $M_{\mathrm{W}} 70 \mathrm{~K}$ (PCL70) & + & + & + \\
\hline (19) Bionolle polybutylene succinate $1001 \mathrm{MD}$ & - & - & - \\
\hline (20) Bionolle polybutylene succinate $1020 \mathrm{MD}$ & - & - & - \\
\hline (21) Bionolle polybutylene succinate-co-adipate & + & + & + \\
\hline (22) Bionolle polybutylene succinate-co-adipate & + & + & + \\
\hline (23) Poly(ethylene succinate) & - & + & - \\
\hline
\end{tabular}

${ }^{a}$ Hydrolytic activity was assayed using agarose plates with emulsified substrates and evaluated based on the formation of a clear zone (halo) in the agarose.

$b_{\text {Solid PLA was used as substrate. }}$ 